
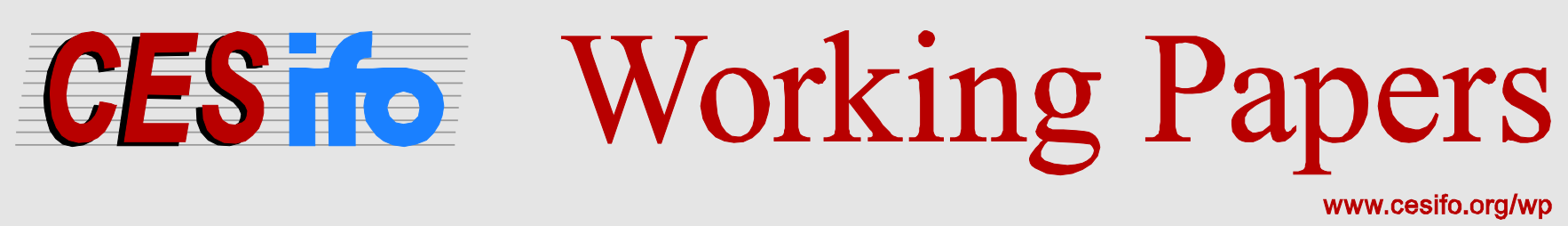

\title{
Allowing Firms to Choose Between Formula Apportionment and Separate Accounting Taxation
}

\author{
Thomas A. Gresik \\ CESIFO WORKING PAPER NO. 4560 \\ CATEGORY 1: PUBLIC FINANCE \\ DECEMBER 2013 \\ An electronic version of the paper may be downloaded \\ - from the SSRN website: Www.SSRN.com \\ - from the RePEc website: Www.RePEc.org \\ - from the CESifo website: www.CESifo-group.org/wp
}




\title{
Allowing Firms to Choose Between Formula Apportionment and Separate Accounting Taxation
}

\begin{abstract}
This paper analyzes the effect on firm behavior and national tax revenues of a policy of allowing multinational firms to choose whether to be taxed under separate accounting rules (transfer prices) or an apportionment formula. Either method can be preferred by low-cost firms and by high-cost firms, and the preferred method can vary non-monotonically with firm cost characteristics. Separate accounting always generates more profitable output and conditional labor demand distortions while either method can generate a more profitable income-shifting distortion. With asymmetric countries, country preferences are only partially aligned with firm preferences due to the fact that countries and firms value tax base distortions differently. With partial alignment of firm and country preferences, choice can increase tax revenues in both countries.
\end{abstract}

JEL-Code: H730, H250, K340.

Keywords: formula apportionment, separate accounting, transfer prices.

\author{
Thomas A. Gresik \\ Department of Economics \\ University of Notre Dame \\ 720 Flanner Hall \\ USA - Notre Dame, IN 46556 \\ tgresik@nd.edu
}

November 2013

Please do not cite without permission.

I thank Andreas Haufler, Kai Konrad, Wolfgang Schön, Dirk Schindler, and participants of the 2013 Skatteforum (Tax Forum) in Norway, the research seminar at the Max Planck Institute for Tax Law and Public Finance in Munich, Germany, and the 8th NorwegianGerman Seminar on Public Economics at CESifo for all their comments. 


\section{Introduction.}

Formula apportionment (FA) and separate accounting (SA) represent two common methods for apportioning a firm's taxable income among the tax jurisdictions in which it operates. Formula apportionment apportions taxable income based on a firm's relative shares of observable economic variables in each jurisdiction such as sales, wages, employment, and capital. Separate accounting apportions taxable income by relying on transfer prices set by the firm and audited by the tax authorities in each location. Both methods distort firm production and sales decisions as well as tax liabilities.

The European Commission and the OECD have taken opposing positions on which approach is preferred with the EC advocating for the adoption of a specific apportionment formula and the OECD favoring a traditional separate accounting approach. ${ }^{2}$ However, the EC (2011) proposal does not recommend the exclusive adoption of an apportionment formula. Rather it defines a policy in which firms operating within the EU can choose between using a specified apportionment formula or standard transfer pricing methods (see page 5 and Chapter III, EC (2011)). In this regard, the EC proposal is similar to current Canadian policy that offers multi-province firms the option of allocating taxable income via an apportionment formula or via transfer prices. ${ }^{3}$ The purpose of this paper is to study the economic implications of allowing each firm to choose the method under which its tax liabilities are calculated.

The most common approach in the extant literature is to compare the equilibrium allocations that result from a specific apportionment formula to those that result from a specific set of transfer price regulations. Key examples of such papers include Nielsen, Raimondos-

\footnotetext{
${ }^{2}$ European Commission (2011) and OECD (2010) describe each organization's position. ${ }^{3}$ Canadian firms make this choice by organizing their multi-province operations according to either a subsidiary-type structure (transfer pricing) or a branch-type structure (formula apportionment). Mintz and Smart (2004) use the choices made by firms to estimate the elasticity of taxable income with respect to tax rates for firms who can engage in income shifting via transfer prices and for those firms that opt to be taxed via an apportionment formula.
} 
Møller, and Schjelderup (2003 and 2010) and Eichner and Runkel (2008 and 2011). ${ }^{4}$ NRS (2003) shows that a shift from SA to FA can actually exacerbate income shifting via transfer prices if the firm operates in oligopoly markets while NRS (2010) shows that tax revenues can either rise or fall from a shift to FA depending on the cost of income shifting and the magnitude of pure firm profits. ER (2008) provides sufficient conditions for a sales-only formula to increase tax revenues relative to SA. ER (2011) endogenizes interest rates and then shows that FA will generate higher tax revenues than SA if the elasticity of substitution between capital and labor is sufficiently large. All of these papers as well as the bulk of this literature study the trade-offs between FA and SA in a complete information model with a representative firm or with identical firms.

Such models have two key limitations. First, tax authorities operate with incomplete information about firm characteristics. This incomplete information provides firms with the ability to engage in tax-induced profit and production shifting and earn information rents. Complete information models are unable to capture the effect of information rents on the performance of any given tax method. For example, they cannot address the Hellerstein and McLure (2004) critique about the practical difficulties of using apportionment formulas that rely on factors (such as capital) whose valuations are difficult for tax authorities to assess due to limited firm information. Second, representative firm models admit no scope for differential firm choice.

One paper that compares FA and SA with private and heterogeneous firm information is Gresik (2010) in which firms have private productivity information, the tax authorities have imperfect auditing technologies, and each country hosts domestic and foreign firms. ${ }^{5}$ In that

\footnotetext{
${ }^{4}$ One exception is Riedel and Runkel (2007) in which a single, representative multinational is required to use an apportionment formula for income generated within a union of countries and to use transfer prices for income generated between union countries and a non-union country. Their model does not allow the firm to choose its method for apportioning its income. ${ }^{5}$ Burbridge, Cuff, and Leach (2006) study profit tax systems for heterogeneous national firms. They do not address the issue of multinational taxation, but do find "substantial differences" in
} 
paper, I show that a sales-only formula will generate greater expected tax revenues than SA as long as the auditing procedures are sufficiently accurate. While this paper does not allow each firm to choose its method of income allocation, it does show that tax revenue differences between FA and SA vary not only with differences in firm productivity but also with the location of a firm's intermediate good production and its final good sales. In addition, the differences in each country's tax revenues need not be monotonic with respect to firm productivity. These results then raise the question of whether countries can earn higher tax revenues by exploiting firm selection patterns.

To study the economic effects associated with firm choice, this paper develops and analyzes a two-country model of heterogeneous multinational firms in which each firm can choose between FA and SA to calculate national tax liabilities. Every firm can produce and sell a final good in each country using local capital and labor while intermediate good production takes place in only one (upstream) country. The model is general enough to allow FA and SA to generate different distortions in final good production, conditional factor demands, and income shifting per unit of the intermediate input, all of which can influence a firm's tax method choice. The model also permits sufficient variation in the countries' final good demands and wages, the intensity of transfer price regulation, and the specific apportionment formula the countries use so that many distinct choice patterns can arise.

A key to understanding the choices made by different firms will be to focus on how a firm's final good output in each country affects the total amount of income it can shift into the low tax rate country under each method. I refer to this connection as the "linkage effect". One illustration of the importance of the linkage effect arises when one examines how each tax method influences a firm operating near its upstream extensive margin. At this extensive

economic outcomes relative to the predictions of complete information studies. Bauer and Langenmayr (2013) study SA with heterogeneous firms but do not study FA. 
margin, a firm is indifferent between selling and not selling in the upstream country. When the upstream country has the higher tax rate and a firm's marginal costs are high enough so that it produces its intermediate good predominately for downstream country sales, a firm can increase its downstream sales in order to engage in increased income shifting under SA while an increase in downstream sales has no effect on the firm's ability to shift income under FA. Thus, the linkage effect implies that firms operating near their upstream country extensive margin will prefer SA.

The after-tax profit differences between FA and SA for a firm that sells its output in both countries can also be understood in terms of how the linkage effect relates distortions in output, conditional labor demand, and income shifting to the total amount of shifted income under each method. Theorem 3 explains how output, conditional labor demand, and income-shifting distortions from small tax rate differentials determine each firm's choice when the countries are otherwise symmetric. The theorem is sufficiently general to be used to evaluate a broad class of output-based apportionment formulas and thus can be used to determine how firm choice patterns can vary with changes in the apportionment formula.

The likelihood that different firms will prefer different methods is greatest when the countries are symmetric since each firm's choice is driven solely by tax rate differences or when there are offsetting asymmetries. Significant differences in wage rates or demand can result in most firms preferring the same method. Examples show that this can happen even with fairly small wage or demand differences. However, wage rate differences tend to push a firm's ranking in the opposite direction as demand differences do. Thus, to the extent that wage rates and demand are positively correlated, a firm's choice can still be primarily driven by the tax rate effects described in Theorem 3.

This paper also studies how firm choice affects tax revenues in each country. Theorem 5 explains how the tax rate differential, the difference in firm profits, and a tax base distortion 
effect determine each country's ranking of FA and SA when the countries are asymmetric. With symmetric countries and small tax rate differences, each firm with sales in both countries will choose the tax method preferred by the low tax rate country (which will also be the less preferred method of the high tax rate country). With asymmetric countries and/or larger tax rate differences, a marginal change in a firm's tax base has a first-order effect on a country's tax revenues but only a second-order effect on a firm's profit. This difference can create a countervailing wedge between firm preferences and country preferences. Now not all firms will prefer the same method as the low tax rate country.

With the possibility for firm choices to be imperfectly aligned with the preferences of the low tax rate country, the potential arises for firm choice to be Pareto improving relative to a policy of requiring all firms to use either SA or FA. The paper shows that choice can be Paretoimproving for two reasons. First, it is possible for a firm's choice to not only improve the firm's after-tax profit but also increase the tax revenues the firm pays to each country. Thus, if the distribution of firm types favors enough of these firms, choice will increase each country's tax revenues. Second, if one generalizes the model to allow for intermediate good production in each country, with the appropriate distribution of firm types, choice can benefit both countries (as well as the firms) even if there is no one firm whose choice results in higher tax revenues paid to each country.

Section 2 presents the model and an example to illustrate the main results of the analysis. In section 3, FA and SA are compared in terms of a firm's profit. The effect of a firm's choice on tax revenues is analyzed in section 4 . Section 5 then discusses the effect of country asymmetries. Section 6 considers the potential for firm choice to be Pareto improving. I offer concluding remarks in section 7 .

\section{The model and an illustrative example.}

In this section, I describe a simple model in which heterogeneous firms can have 
differential preferences over being taxed under a formula apportionment system or a separate accounting system. I then provide an example to highlight the key analytic results of the paper.

There are two countries ( 1 and 2$)$ and a continuum of multinational firms. Each multinational operates a subsidiary in each country. Denote country $j$ 's tax rate by $t_{j}$. Given $t_{1}$ and $t_{2}$, each multinational chooses the tax system under which it will operate, if needed it sets a transfer price for any intermediate goods produced by one subsidiary and transferred to the other, and it makes production and sales decisions in each country.

Every multinational firm owns a subsidiary in each country which is responsible for producing and selling a final good using labor, capital, and an intermediate good. All final good production is sold locally. Intermediate good production occurs only in country 1 and uses both labor and capital. The final good production function in each country is $\min \left\{z, F\left(k_{i}^{f}, l_{i}^{f}\right)\right\}$ where $z$ denotes the quantity of the intermediate good used, $k_{j}^{f}$ denotes the quantity of capital used in country $j$ for final good production, and $l_{j}^{f}$ denotes the quantity of labor used in county $j$ for final good production. Note that one unit of the intermediate good is required to produce one unit of the final good while the firm can substitute between capital and labor. The sub-production function, $F$, exhibits constant returns to scale. The intermediate good production function is $G\left(k^{i}, l^{i} ; \theta\right)=\min \left\{k^{i}, l^{i} / \theta\right\}$ where $k^{i}$ denotes the quantity of capital used in intermediate good production, $l^{i}$ denotes the quantity of labor used in intermediate good production, and $\theta$ is a parameter that determines if intermediate good production is more $(\theta>1)$ or less $(\theta<1)$ labor intensive. While the Leontief production function for the intermediate good is admittedly simple in nature, the production structure in the model is rich enough to generate non-trivial firm choice patterns and to allow one to identify the key economic channels through which each tax method influences the choice patterns. Denote the marginal economic cost of capital for a firm by $\mu$. Variation among firms in $\theta$ or $\mu$, reflecting either potential differences in productivity or potential differences in the internal projects available to each firm, will constitute the two 
possible sources of firm heterogeneity in this model and will account for variation in firm preferences of FA and SA. Denote the cdf of firm types by $\Phi(\mu, \theta){ }^{6}$

Denote the country $j$ wage rate by $w_{j}$. Labor in each country is immobile and each firm takes the wage rate in each country as given. Given the novelty of studying firm choice even in a partial equilibrium setting, I leave the study of general equilibrium effects to future work.

Each firm serves market $j$ with inverse demand function $p_{j}\left(q_{j}\right)$. Assume for each country $j$ that $p_{j}(0)$ is finite and there exists a quantity $\bar{q}_{j}$ such that for all $q_{j} \geq \bar{q}_{j}, p_{j}\left(q_{j}\right)=0$. Define a firm's revenue function in each country $j$ by $r_{j}\left(q_{j}\right)$ where $q_{j}$ denotes the quantity of the final good produced and sold in country $j . r_{j}(0)=0$ and $r_{j}^{\prime}(0)=p_{j}(0)>0$. For each $j$, assume that $r_{j}(\cdot)$ is strictly concave and that $p_{j}(0)$ is finite. A multinational's pre-tax operating profit in country 1 equals $r_{1}\left(q_{1}\right)-w_{1}\left(l_{1}^{f}+l^{i}\right)-\mu\left(k_{1}^{f}+k_{2}^{f}+k^{i}\right)$ and its pre-tax operating profit in country 2 equals $r_{2}\left(q_{2}\right)-w_{2} l_{2}^{f}-\mu k_{2}^{f}$.

To emphasize the role of tax rate differences, it will help to analyze the case of symmetric countries. When country symmetry is invoked it will mean that the revenue functions and the wage rates are identical: $r_{1}(q)=r_{2}(q)$ for all $q$ and $w_{1}=w_{2}$.

With SA, each firm sets a transfer price that determines how much the subsidiary in country 2 pays the subsidiary in country 1 for the units of the intermediate good it uses. Denote this transfer price by $\rho$. The countries jointly audit each firm's transfer price to limit the amount of income-shifting induced by tax rate differentials. Per-unit audit costs incurred by a multinational are denoted by the strictly convex function $C\left(\rho-\theta w_{1}\right)$ for which $C(\cdot) \geq 0$ and $C(0)=0 .{ }^{7}$ Positive audit costs can reflect the costs incurred by the firm to defend its transfer price during an audit as well as expected penalties imposed by the tax authorities. Writing $C(\cdot)$

\footnotetext{
${ }^{6}$ Most of the examples will focus on variation in $\mu$ for convenience except when the results with regard to $\theta$ differ.

${ }^{7}$ This specification abstracts from actual transfer price regulations under which the auditing costs vary with the tax rates but shares the same qualitative properties mentioned in the text. See Gresik and Osmundsen (2008) and Nielson, Raimondos-Møller, and Schjelderup (2010) for models that incorporate this level of detail in their models.
} 
as a function of $\rho-\theta w_{1}$ implies an arm's-length price for the intermediate good of $\theta w_{1}$ since deviations from this price reflect income-shifting by the multinational. If $\rho<\theta w_{1}$, the multinational is shifting taxable income into country 2 and if $\rho>\theta w_{1}$, the multinational is shifting taxable income into country 1. An alternative definition of the arm's-length price would be $\theta w_{1}+\mu$. Since capital costs are generally not $100 \%$ tax-deductible, using this alternative definition of an arm's-length price would effectively allow firms to use non-tax-deductible costs to shift some taxable income at no (auditing) cost.

For a firm that chooses to be taxed under a separate accounting system, its global post-tax economic profit equals

$$
\begin{aligned}
\bar{\pi}^{S A}\left(q_{1}, q_{2}, \rho, l_{1}^{f}, l_{2}^{f}, l^{i}, k_{1}^{f}, k_{2}^{f}, k^{i}\right)=\left(1-t_{1}\right)\left(r_{1}\left(q_{1}\right)-w_{1}\left(l_{1}^{f}+l^{i}\right)+\rho q_{2}\right) \\
+\left(1-t_{2}\right)\left(r_{2}\left(q_{2}\right)-w_{2} l_{2}^{f}-\rho q_{2}\right)-C\left(\rho-\theta w_{1}\right) q_{2}-\mu\left(k_{1}^{f}+k_{2}^{f}+k^{i}\right) .
\end{aligned}
$$

Note that total audit costs equal $C(\cdot) q_{2}$. Defining total audit costs in this way emphasizes the fact that since income-shifting is proportional to the volume of intermediate good shipments so too are the costs of income-shifting. Also note that most countries do not permit the full taxdeductibility of capital costs. For simplicity, I assume that $100 \%$ of capital costs are not taxdeductible.

With FA, each firm reports its total taxable income to each country. An apportionment formula is then used to divide the total taxable income between the two countries. In this paper, I restrict attention to apportionment formulas defined by $\lambda\left(q_{1}, q_{2}\right)$, which determines the fraction of global taxable income taxed in country 1 , such that $0 \leq \lambda\left(q_{1}, q_{2}\right) \leq 1, \lambda_{1}\left(q_{1}, q_{2}\right) \equiv \partial \lambda / \partial q_{1} \geq 0$ (with equality only if $\lambda=1$ ), and $\lambda_{2}\left(q_{1}, q_{2}\right) \equiv \partial \lambda / \partial q_{2} \leq 0$ (with equality only if $\lambda=0$ ). In addition, $\lambda\left(q_{1}, 0\right)$ must equal one as the firm is not operating in country 2 . However, $\lambda\left(0, q_{2}\right)$ need not equal zero as the firm is still producing the intermediate good in country 1 . Given $\lambda\left(q_{1}, q_{2}\right)$, the effective tax rate for a firm will be 


$$
T=\lambda\left(q_{1}, q_{2}\right) t_{1}+\left(1-\lambda\left(q_{1}, q_{2}\right)\right) t_{2} .
$$

Thus, under FA a firm shifts income between countries by adjusting its output levels in each country in order to alter its effective tax rate.

Two examples of apportionment formulas with this structure are the output formula, $\lambda=q_{1} /\left(q_{1}+q_{2}\right)$, and the sales-only formula, $\lambda=r_{1}\left(q_{1}\right) /\left(r_{1}\left(q_{1}\right)+r_{2}\left(q_{2}\right)\right){ }^{8}$ This specification does not include formulas that depend on inputs such as wages, employment, and/or capital (see footnote 11$)^{9}$

An apportionment formula will be called symmetric if there is a non-negative, nondecreasing function, $\Lambda\left(q_{i}\right)$ with $\Lambda(0)=0$ so that $\lambda\left(q_{1}, q_{2}\right)=\Lambda\left(q_{1}\right) /\left(\Lambda\left(q_{1}\right)+\Lambda\left(q_{2}\right)\right)$. For symmetric apportionment formulas, $\lambda\left(q_{i}, q_{i}\right)=1 / 2, \lambda_{1}\left(q_{i}, q_{i}\right)+\lambda_{2}\left(q_{i}, q_{i}\right)=0, \lambda_{12}\left(q_{i}, q_{i}\right)=0$, and $\lambda_{11}\left(q_{i}, q_{i}\right)+\lambda_{22}\left(q_{i}, q_{i}\right)=0$. An apportionment formula will be symmetric if it does not bias operations in one country over the other. Examples of symmetric formulas include the output formula and the sales-only formula when the firms operate in symmetric countries. Given (2), a firm's post-tax economic profit is

$$
\bar{\pi}^{F A}\left(q_{1}, q_{2}, k_{1}^{f}, k_{2}^{f}, k^{i}, l_{1}^{f}, l_{2}^{f}, l^{i}\right)=(1-T)\left(r_{1}\left(q_{1}\right)+r_{2}\left(q_{2}\right)-w_{1}\left(l_{1}^{f}+l^{i}\right)-w_{2} l_{2}^{f}\right)-\mu\left(k_{1}^{f}+k_{2}^{f}+k^{i}\right) .
$$

Regardless of the tax method chosen, each firm chooses its outputs, factor demands, and transfer price to maximize its post-tax profit. Both SA and FA will distort these output, factor demand, and transfer price choices. Denote a firm's post-tax indirect profits under SA and FA by $\Pi^{S A}\left(t_{1}, t_{2}, w_{1}, w_{2}, \mu, \theta\right)$ and $\Pi^{F A}\left(t_{1}, t_{2}, w_{1}, w_{2}, \mu, \theta\right)$. Each firm will prefer the tax method that generates higher indirect profit while each country prefers that a firm choose the method that generates higher tax revenues. Several distortions will determine how a firm's preferred method and each country's preferred method vary with a firm's characteristics ( $\mu$ and $\theta$ ). The following

\footnotetext{
${ }^{8}$ If marginal revenue can be negative, the sales-only formula can violate either $\lambda_{1} \geq 0$ or $\lambda_{2} \leq 0$. However, both of these cases can be shown not to be profit-maximizing. ${ }^{9}$ Each SA method is equivalent to a specific apportionment formula but not necessarily one defined by a formula $\lambda\left(q_{1}, q_{2}\right)$.
} 
example offers a road map to help understand what these various distortions are and how they interact and to provide a context for the paper's formal analytic results.

An illustrative example.

Consider an example in which $r_{i}\left(q_{i}\right)=\left(a_{i}-q_{i}\right) q_{i}, F\left(k_{i}^{f}, l_{i}^{f}\right)=\min \left\{k_{i}^{f}, l_{i}^{f}\right\}$, $C\left(\rho-\theta w_{1}\right)=\left(\rho-\theta w_{1}\right)^{2}$, and $\lambda\left(q_{1}, q_{2}\right)=r_{1}\left(q_{1}\right) /\left(r_{1}\left(q_{1}\right)+r_{2}\left(q_{2}\right)\right){ }^{10}$ These assumptions will be maintained for all the examples presented in this paper. Figures $1-4$ describe how a firm's indirect profits and each country's tax revenues differ under FA and SA as a function of a firm's marginal cost of capital, $\mu$. The thin line in each figure represents $\Pi^{S A}-\Pi^{F A}$, the solid thick line represents country 1 tax revenues under SA minus those under FA, and the dashed line represents country 2 tax revenues under SA minus those under FA. Positive values of each curve indicate a preference for SA while negative values indicate a preference for FA.

Figures 1 and 2 correspond to the case in which the countries are symmetric, each with a wage of 1 and a choke-off price of 20 . For Figure $1, t_{1}=.29$ and $t_{2}=.30$. For Figure $2, t_{1}=.30$ and $t_{2}=.29$. Figures 3 and 4 correspond to cases in which the countries are asymmetric. For Figure 3, country 1 has larger demand, $a_{1}=20$ and $a_{2}=18$, higher wages, $w_{1}=1$ and $w_{2}=.9$, and a higher tax rate, $t_{1}=.50$ and $t_{2}=.30$. For Figure 4 , the tax rates are reversed. Intensive margin effects: In Figures 1 and 2, each firm with a value of $\mu$ less than 6.3 (approximately) will sell its product in both countries. For these firms, FA and SA distortions affect their intensive operating margins (on $q_{1}$ and $q_{2}$ ). Among firms that sell in both countries, those with low values of $\mu$ prefer SA while those with high values prefer FA. In general, it is possible to generate a variety of selection patterns with respect to both $\mu$ and $\theta$ including patterns for which all firm types prefer the same method and patterns in which firm choice varies with a firm's type. The particular selection pattern that arises can be understood in terms of how the

\footnotetext{
${ }^{10}$ This example implies that $C^{\prime \prime}(0)=-r_{i}^{\prime \prime}\left(q_{i}\right)=2$. None of the qualitative properties of the example rely on this equivalence and none of the formal propositions require any restrictions on the relationship between $C^{\prime \prime}(0)$ and $r_{i}^{\prime \prime}\left(q_{i}\right)$.
} 
two methods vary with respect to the output, conditional labor demand, and income-shifting distortions they create. Theorem 3 describes how these three sources of intensive margin distortions interact when the (symmetric) countries' tax rates are similar as this is when a firm's choice is determined almost exclusively by the tax rate differential. Figures 1 and 2 also show that for each firm its choice is the same as the low tax rate country's preferred method and the opposite of the high tax rate country's preferred method. Theorem 4 explains why this is the case for symmetric countries.

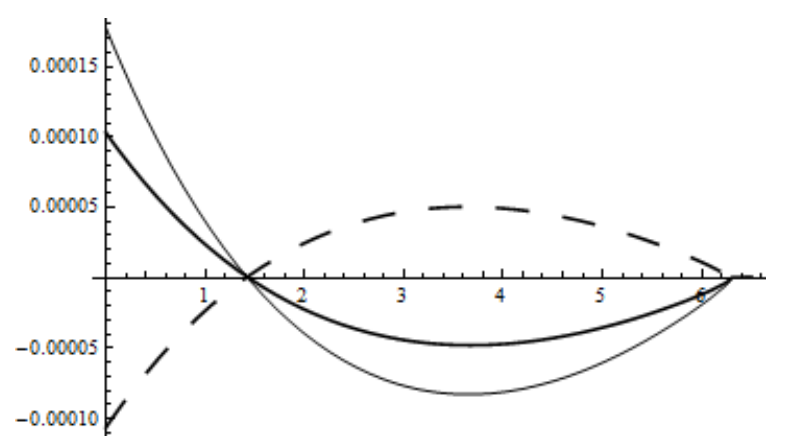

Figure 1: The difference of indirect firm profit (thin line), country 1 tax revenues (thick line), and country 2 tax revenues (dashed line) under SA minus under FA as a function of $\mu$ when $w_{1}$ $=w_{2}=1, a_{1}=a_{2}=20, t_{1}=.29$, and $t_{2}=.30$.

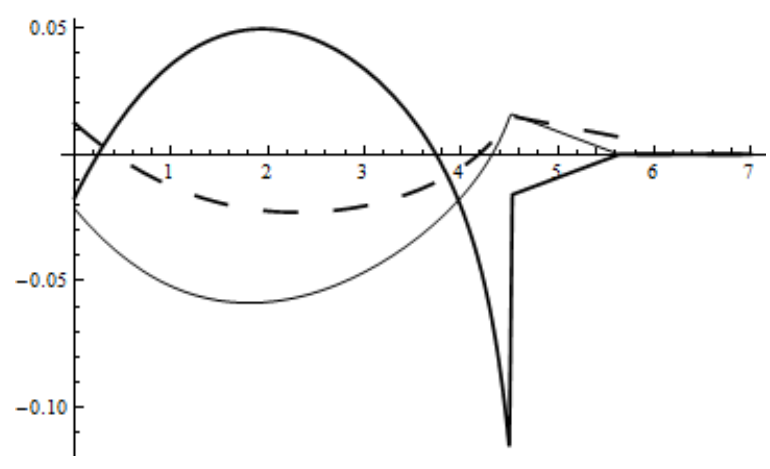

Figure 3: The difference of indirect firm profit (thin line), country 1 tax revenues (thick line), and country 2 tax revenues (dashed line) under SA minus under FA as a function of $\mu$ when $w_{1}$ $=1, w_{2}=.9, a_{1}=20, a_{2}=18, t_{1}=.50$, and $t_{2}=$ .30 .

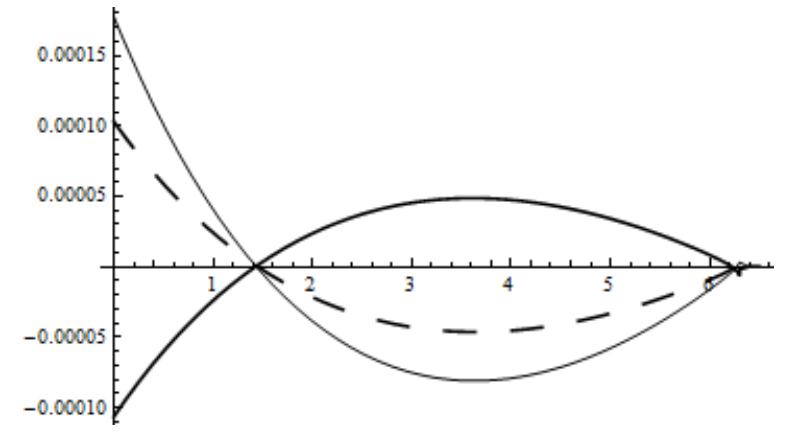

Figure 2: The difference of indirect firm profit (thin line), country 1 tax revenues (thick line), and country 2 tax revenues (dashed line) under SA minus under FA as a function of $\mu$ when $w_{1}$ $=w_{2}=1, a_{1}=a_{2}=20, t_{1}=.30$, and $t_{2}=.29$.

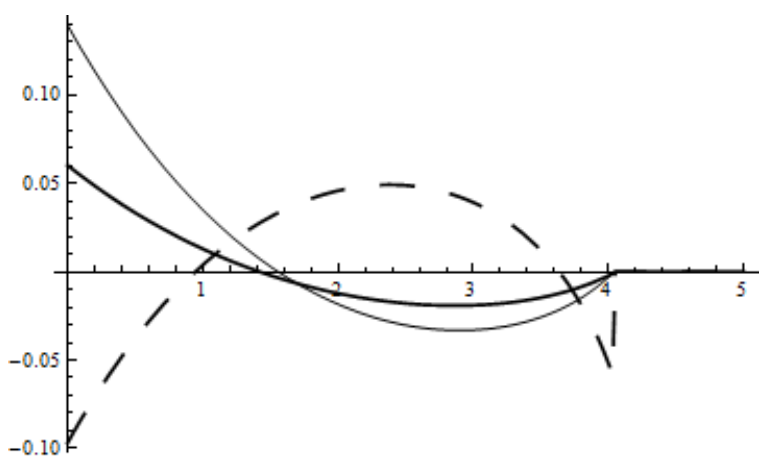

Figure 4: The difference of indirect firm profit (thin line), country 1 tax revenues (thick line), and country 2 tax revenues (dashed line) under SA minus under FA as a function of $\mu$ when $w_{1}$ $=1, w_{2}=.9, a_{1}=20, a_{2}=18, t_{1}=.30$, and $t_{2}=$ .50 . 
Extensive margin effects: The firm profit line in Figure 3 reveals a new effect for values of $\mu$ between 4.5 and 5.6. In this range, a firm sells its product only in country 2 . For $\mu \geq 5.6$, output is zero in both countries. At $\mu=4.5$, the firm is operating at its country 1 extensive margin since it is just indifferent between selling and not selling in country 1 . Thus, this firm prefers SA as FA no longer provides any opportunity for income-shifting whereas the linkage of country 2 output with country 1 intermediate good production continues to afford a channel for shifting income into country 2 (with the lower tax rate). As Figure 3 reveals, this extensive margin effect applies to all firms that only sell in country 2 and this effect interacts with the intensive margin effects for firms with $\mu$ below but close to 4.5 . Theorems 1 and 2 formally describe when the country 1 extensive margin effect or the country 2 extensive margin effect arises and how it influences a firm's choice.

Alignment/misalignment of firm and country preferences: Figures 3 and 4 show that firm preferences need no longer be perfectly aligned with the preferences of the low tax rate country nor perfectly opposed to the preferences of the high tax country. For example, in Figure 3 with $\mu$ close to zero, the firm's preference for FA is aligned with high tax rate country 1's preference and misaligned with low tax rate country 2's preference. This lack of full alignment/misalignment is due to both country asymmetries and significant tax rate differences that cause the firm and the countries to value tax base distortions differently. Theorem 5 explains how wage and demand asymmetries influence the alignment of a firm's choice with each country's preferred method. Pareto-improving choice: In Figure 3, note that for $\mu$ between 3.8 and 4.2 the firm and both countries prefer FA. One concern expressed by larger, higher wage, higher tax rate countries in the EU is that firm choice will result in them earning lower tax revenues. This figure shows that this outcome need not occur. Relative to the current policy in which all firms must use SA, allowing firms to choose between SA and FA can be Pareto improving if the distribution of firm types is largely concentrated on firms in this type range. This makes the question of Pareto- 
improving choice an empirical issue. A similar result arises in Figure 4, for $\mu$ between 3.8 and 4 . For $\mu$ between 1 and 1.4, the firm and both countries prefer SA. While the countries would realize no gain in tax revenues from these firms from choice relative to mandating SA, they would realize a gain in tax revenues from choice relative to mandating FA. Again, the potential for choice to be Pareto improving is made possible due to the effects of country asymmetries described in Theorem 5 and sizeable extensive margin effects.

\section{Multinational decisions.}

Each multinational maximizes its global post-tax profit taking as given the tax rates, the wage rates, its marginal economic cost of capital, and its technology for producing the intermediate good.

\subsection{Separate accounting.}

The problem each multinational solves is to maximize (1) subject to $q_{j} \leq F\left(k_{j}^{f}, l_{j}^{f}\right)$ for $j \in\{1,2\}$ and $q_{1}+q_{2} \leq G\left(k^{i}, l^{i} ; \theta\right)$. Holding $q_{1}, q_{2}$, and $\rho$ fixed, a firm's conditional factor demands, $K_{i}^{S A}$ and $L_{i}^{S A}$, are solutions to standard after-tax cost-minimization problems so that $k^{i}=q_{1}+q_{2}, l^{i}=\theta\left(q_{1}+q_{2}\right)$, and $K_{i}^{S A}\left(q_{i}, t_{i}\right)$ and $L_{i}^{S A}\left(q_{i}, t_{i}\right)$ satisfy $F\left(k_{i}^{f}, l_{i}^{f}\right)=q_{i}$ and $F_{K} / \mu=F_{L} /\left(1-t_{i}\right) w_{i}$ where the " $K$ " and " $L$ " subscripts denote partial derivatives of the subproduction function. Note that $K_{i}^{S A}$ and $L_{i}^{S A}$ do not depend on $q_{j}$ or $t_{j}$.

Differentiating (1) with respect to $\rho$ implies that a firm's optimal transfer price satisfies $t_{2}-t_{1}=C^{\prime}\left(\rho-\theta w_{1}\right)$ or $\rho=\theta w_{1}+\left(C^{\prime}\right)^{-1}\left(t_{2}-t_{1}\right)$. If the magnitude of this optimal transfer price is too large, the firm's problem can be unbounded due to the ability of the firm to produce arbitrarily large quantities in country 2 to shift arbitrarily large profit into country $2(\rho<0)$ or into country $1\left(\rho>r_{2}\left(q_{2}\right) / q_{2}-w_{2}\right)$. Many countries have a "commensurate with income" provision in their tax codes that limit such extreme profit-shifting. However, as long as $C(\cdot)$ is sufficiently convex, such extreme values of $\rho$ will not be profit maximizing. Thus, in what follows I assume that indirect profit under SA is finite for all firm types in the economy. 
Substituting the conditional factor demands and the optimal transfer price into (1) implies that a firm solves its profit-maximization problem by choosing $q_{1}$ and $q_{2}$ to maximize

$$
\begin{aligned}
\pi^{S A}\left(q_{1}, q_{2}\right)= & \left(1-t_{1}\right)\left(r_{1}\left(q_{1}\right)-w_{1}\left(L_{1}^{S A}\left(q_{1}, t_{1}\right)+\theta q_{1}\right)\right)+\left(1-t_{2}\right)\left(r_{2}\left(q_{2}\right)-w_{2} L_{2}^{S A}\left(q_{2}, t_{2}\right)-w_{1} \theta q_{2}\right) \\
& +\Delta\left(t_{1}, t_{2}\right) q_{2}-\mu\left(K_{1}^{S A}\left(q_{1}, t_{1}\right)+K_{2}^{S A}\left(q_{2}, t_{2}\right)+q_{1}+q_{2}\right)
\end{aligned}
$$

where $\Delta\left(t_{1}, t_{2}\right)=\left(t_{2}-t_{1}\right)\left(C^{\prime}\right)^{-1}\left(t_{2}-t_{1}\right)-C\left(\left(C^{\prime}\right)^{-1}\left(t_{2}-t_{1}\right)\right) . \Delta\left(t_{1}, t_{1}\right)=0$ for all $t_{1}$ and for all $t_{2} \neq t_{1}$, $\Delta\left(t_{1}, t_{2}\right)>0$ by the strict convexity of $C(\cdot) . \pi^{S A}\left(q_{1}, q_{2}\right)$ is strictly concave in $q_{1}$ and $q_{2}$. Denote the profit-maximizing quantities by $q_{1}^{S A}\left(t_{1}, t_{2}, w_{1}, w_{2}, \mu, \theta\right)$ and $q_{2}^{S A}\left(t_{1}, t_{2}, w_{1}, w_{2}, \mu, \theta\right)$. Evaluating (4) at these optimal quantities yields a firms' indirect profit, $\Pi^{S A}\left(t_{1}, t_{2}, w_{1}, w_{2}, \mu, \theta\right)$.

By the Envelope Theorem,

$$
\partial \Pi^{S A} / \partial \mu=-\left(K_{1}^{S A}\left(q_{1}^{S A}\right)+K_{2}^{S A}\left(q_{2}^{S A}\right)+q_{1}^{S A}+q_{2}^{S A}\right)<0 .
$$

Direct comparative statics calculations further imply for $i \in\{1,2\}$ that $\partial q_{i}^{S A} / \partial \mu<0$. Thus, multinationals with higher economic costs of capital earn lower post-tax profit and produce less in each country. Note also that firm profit is linear in $\mu$ if one holds output or input levels constant. Any change in output and input levels from a change in $\mu$ must yield higher profit than this passive benchmark. Thus, $\Pi^{S A}$ must also be convex in $\mu$.

For sufficiently large values of $\mu$, a firm will no longer find it profitable to sell in country 1 and/or country 2. Define $\mu_{i}^{S A}$ so that, for all $\mu \geq \mu_{i}^{S A}, q_{i}^{S A}=0$. Lemma 1 explains how to rank $\mu_{1}^{S A}$ and $\mu_{2}^{S A}$.

Lemma 1. If the countries are symmetric and demand is sufficiently large, then $\left(\mu_{1}^{S A}-\mu_{2}^{S A}\right)\left(t_{1}-t_{2}\right)<0$ for all $t_{1} \neq t_{2}$.

Lemma 1 states that, absent country asymmetries, a firm operating under SA will shut down sales in the high tax rate country before it shuts down sales in the low tax rate country.

With regard to $\theta$, the Envelope Theorem implies that less productive firms earn less indirect profit as

$$
\partial \Pi^{S A} / \partial \theta=-\left(1-t_{1}\right) w_{1} q_{1}^{S A}-\left(1-t_{2}\right) w_{1} q_{2}^{S A}<0 .
$$


Less productive firms also sell less in each country as $\partial q_{i}^{S A} / \partial \theta$ is negative for $i \in\{1,2\}$. By the same argument used in the preceding paragraph, $\Pi^{S A}$ is convex in $\theta$. An analog to Lemma 1 exists with respect to critical values of $\theta$ as well.

\subsection{Formula apportionment.}

Each firm's problem is to maximize (3) subject to $q_{j} \leq F\left(k_{j}^{f}, l_{j}^{f}\right)$ for $j \in\{1,2\}$ and $q_{1}+q_{2} \leq G\left(k^{i}, l^{i} ; \theta\right)$. Holding $q_{1}$ and $q_{2}$ fixed, a firm's conditional factor demands, $K_{i}^{F A}$ and $L_{i}^{F A}$, are solutions to standard after-tax, cost-minimization problems so that $k^{i}=q_{1}+q_{2}$, $l^{i}=\theta\left(q_{1}+q_{2}\right)$, and $K_{i}^{F A}\left(q_{1}, q_{2}\right)$ and $L_{i}^{F A}\left(q_{1}, q_{2}\right)$ satisfy $F\left(k_{i}^{f}, l_{i}^{f}\right)=q_{i}$ and $F_{K} / \mu=F_{L} /(1-T) w_{i}$. Note that, because both output quantities influence the effective tax rate, the conditional factor demands depend on both quantities. ${ }^{11}$

Substituting these conditional demands into (3) implies that a firm solves its profitmaximization problem by choosing $q_{1}$ and $q_{2}$ to maximize

$$
\pi^{F A}\left(q_{1}, q_{2}\right)=(1-T) \pi^{0}\left(q_{1}, q_{2}\right)-\mu\left(K_{1}^{F A}+K_{2}^{F A}+q_{1}+q_{2}\right)
$$

where

$$
\pi^{0}\left(q_{1}, q_{2}\right)=r_{1}\left(q_{1}\right)+r_{2}\left(q_{2}\right)-w_{1}\left(L_{1}^{F A}\left(q_{1}, q_{2}\right)+\theta\left(q_{1}+q_{2}\right)\right)-w_{2} L_{2}^{F A}\left(q_{1}, q_{2}\right)
$$

denotes a firm's global pre-tax taxable profit. Unlike in the SA case, $\pi_{12}^{F A} \neq 0$, as now both $q_{1}$ and $q_{2}$ affect $T$. Moreover, $\pi^{F A}$ need not be globally concave in $q_{1}$ and $q_{2}$. However, the market bounds, $\bar{q}_{1}$ and $\bar{q}_{2}$, imply that profit-maximizing quantities exist. Denote these quantities by $q_{1}^{F A}\left(t_{1}, t_{2}, w_{1}, w_{2}, \mu, \theta\right)$ and $q_{2}^{F A}\left(t_{1}, t_{2}, w_{1}, w_{2}, \mu, \theta\right)$. Evaluating (7) at these optimal quantities yields the firm's indirect economic profit, $\Pi^{F A}\left(t_{1}, t_{2}, w_{1}, w_{2}, \mu, \theta\right)$.

By the Envelope Theorem,

$$
\partial \Pi^{F A} / \partial \mu=-\left(K_{1}^{F A}+K_{2}^{F A}+q_{1}^{F A}+q_{2}^{F A}\right)<0
$$

and since the equilibrium quantities must be incentive compatible,

${ }^{11}$ If one were to consider apportionment formulas that use input shares or input-cost shares, it need no longer be the case that $q_{j}=F\left(K_{j}^{F A}, L_{j}^{F A}\right)$ as some firms might have an incentive to overemploy capital or labor in order to influence $T$. 


$$
\left(\partial K_{1}^{F A} / \partial q_{1}+1\right) \partial q_{1}^{F A} / \partial \mu+\left(\partial K_{2}^{F A} / \partial q_{2}+1\right) \partial q_{2}^{F A} / \partial \mu \leq 0 .
$$

Note that (8) and (9) hold for all apportionment formulas and not just quantity-based formulas.

The ability of a firm to adjust its output and input levels in response to a change in $\mu$ implies that $\Pi^{F A}$ is convex in $\mu$.

Lemma 2. If the countries are symmetric, then $\left(\mu_{1}^{F A}-\mu_{2}^{F A}\right)\left(t_{1}-t_{2}\right)<0$ for all $t_{1} \neq t_{2}$.

Lemma 2 is the analog to Lemma 1 for FA. Under FA, a firm will sell more in the low tax rate country than in the high tax rate country, and as a result, it will first shut down sales in the high tax rate country.

For firms with different productivity parameters,

$$
\partial \Pi^{F A} / \partial \theta=-(1-T) w_{1}\left(q_{1}^{F A}+q_{2}^{F A}\right)<0,
$$

and since the equilibrium quantities must be incentive compatible,

$$
\left((1-T) w_{1}+\left(t_{2}-t_{1}\right) \lambda_{1}\right) \partial q_{1}^{F A} / \partial \theta+\left((1-T) w_{1}+\left(t_{2}-t_{1}\right) \lambda_{2}\right) \partial q_{2}^{F A} / \partial \theta \leq 0 .
$$

$\Pi^{F A}$ is convex in $\theta$. Analogs to Lemmas 1 and 2 exist with regard to variation in $\theta$.

\subsection{Multinational selection.}

The analysis in sections 3.1 and 3.2 reveals that the global post-tax indirect profit functions under FA and SA are decreasing convex functions of $\mu$ and of $\theta$. Each firm's choice of a tax method will be based on the difference in its indirect profit functions, $\Pi^{S A}-\Pi^{F A}$, and each method provides firms with distinct profit-shifting channels: transfer pricing with SA and production and sales shifting with FA. Moreover, both systems rely on the linkage of upstream (country 1) intermediate good production with downstream (country 2) sales in order to actually shift profits. To highlight the importance of this linkage effect on a firm's preference between FA and SA, we focus first on a firm's preferences when a preponderance of its sales occur in one country (section 3.3.1) as this is where extensive margin effects are evident and when the firm operates in symmetric countries with a focus on the intensive margin effects (section 3.3.2). 


\subsubsection{Extensive margin effects (Dominant country sales).}

A firm will choose to sell almost exclusively in one country if the firm's marginal cost of capital is sufficiently high; country differences then determine in which country almost all of a firm's sales occur. Theorem 1 considers the case in which a firm's marginal cost of capital is sufficiently high and most of its sales occur in country 2.

Theorem 1. Assume that $\bar{\mu}_{1} \equiv \max \left\{\mu_{1}^{S A}, \mu_{1}^{F A}\right\}<\min \left\{\mu_{2}^{S A}, \mu_{2}^{F A}\right\} \equiv \underline{\mu}_{2}$. There exists $\hat{\mu}<\bar{\mu}_{1}$ such that a firm with marginal cost of capital $\mu \in\left(\hat{\mu}, \underline{\mu}_{2}\right)$ strictly prefers $S A$ over $F A$.

The interval, $\left[\bar{\mu}_{1}, \underline{\mu}_{2}\right)$, corresponds to marginal capital costs for which a firm would sell nothing in country 1 and strictly positive quantities in country 2 under SA and FA. A necessary condition for this range to be well-defined under country symmetry is $t_{1}>t_{2}$. For these values of $\mu$, a firm strictly prefers SA over FA because FA affords no profitable opportunities for profitshifting as the firm always faces an effective tax rate of $t_{2}$ while SA still allows the firm to shift profits via transfer pricing. By continuity, this preference order extends to firms with marginal capital costs slightly below $\bar{\mu}_{1}$ so that country 2 is the predominant but not exclusive sales location. With negligible sales in country 1, the firm's ability to shift profits under FA is also very limited while its country 2 production affords greater potential to shift profits under SA. Figure 3 provides an illustration of Theorem 1 where $\bar{\mu}_{1}=4.5$ and $\underline{\mu}_{2}=5.6$.

Theorem 2 considers the mirror-image case in which almost all of a firm's sales occur in country 1 . Now it is the case that $\bar{\mu}_{2} \equiv \max \left\{\mu_{2}^{S A}, \mu_{2}^{F A}\right\}<\min \left\{\mu_{1}^{S A}, \mu_{1}^{F A}\right\} \equiv \underline{\mu}_{1}$. (With symmetric countries, this case arises when $t_{1}<t_{2}$.) For $\mu$ between $\bar{\mu}_{2}$ and $\underline{\mu}_{1}$, a firm sells only in country 1 under FA and SA and earns equal post-tax profit under each method. Now a firm's choice when $\mu$ is just below $\bar{\mu}_{2}$ depends on whether it prefers to sell nothing in country 2 under SA before it sells nothing in country 2 under FA.

Theorem 2. Assume that $\bar{\mu}_{2} \equiv \max \left\{\mu_{2}^{S A}, \mu_{2}^{F A}\right\}<\min \left\{\mu_{1}^{S A}, \mu_{1}^{F A}\right\} \equiv \underline{\mu}_{1}$. There exists $\hat{\mu}<\bar{\mu}_{2}$ such that a firm with marginal cost of capital $\mu \in\left(\hat{\mu}, \bar{\mu}_{2}\right)$ strictly prefers to be taxed under $F A$ if, 
$\mu_{2}^{S A}<\mu_{2}^{F A}$ and it strictly prefers to be taxed under $S A$ if $\mu_{2}^{F A}<\mu_{2}^{S A}$.

The economic conditions that generate this case limit the firm's ability to shift profits near its country 2 extensive margin under either method as the magnitude of shifted profits is tied via the linkage effect to country 2 sales. Theorem 2 identifies the preferred tax method for firms that predominately sell in country 1 with the method that supports higher country 2 sales because that method offers the greater, although modest, capacity for profit-shifting. For example, when $\mu_{2}^{S A}<\mu_{2}^{F A}$, a firm with $\mu=\mu_{2}^{S A}$ would still prefer to sell positive quantities in both countries under FA but sell only in country 1 under SA. If this firm chose FA but sold its output only in country 1, it would earn the same profit as it could by choosing SA and selling only in country 1 . Since it prefers to sell positive quantities in both countries under FA, the strict concavity of pretax profits implies that its profits must be strictly higher under FA. An analogous argument shows why a firm's preferred method switches when $\mu_{2}^{F A}<\mu_{2}^{S A}$.

Figures 5 and 6 illustrate both Theorem 2 scenarios. Figures 5 and 6 share the same assumptions and parameter values used for Figure 1 except that for Figure 5, $w_{1}=1, t_{1}=.3$, and $t_{2}=.5$, while for Figure $6, w_{1}=.5, t_{1}=.3$, and $t_{2}=.5$. The kink in Figure 5 around $\mu=4.6$ coincides with $\bar{\mu}_{2}$, the value of $\mu$ beyond which a firm sells only in country 1 . Figure 5 corresponds to the case in Theorem 2 for which $\mu_{2}^{S A}<\mu_{2}^{F A}$. As a result, a firm with a value of $\mu$ slightly below $\bar{\mu}_{2}$ strictly prefers FA. Figure 6 corresponds to the case in Theorem 2 for which $\mu_{2}^{F A}<\mu_{2}^{S A}$. Now a firm with a value of $\mu$ slightly below $\bar{\mu}_{2}$ at around 4.67 strictly prefers SA.

The effect of wage rate differences on the ordering of $\mu_{2}^{S A}$ and $\mu_{2}^{F A}$ can be seen by comparing marginal profits with respect to country 2 sales at $q_{2}=0$ under each method where

$$
\left.\left(\frac{\partial \pi^{S A}}{\partial q_{2}}-\frac{\partial \pi^{F A}}{\partial q_{2}}\right)\right|_{\mu=\mu_{2}^{F A}}=\Delta\left(t_{1}, t_{2}\right)-\left(t_{2}-t_{1}\right)\left(r_{2}^{\prime}(0)-w_{1} \theta\right)-\left(t_{2}-t_{1}\right) \lambda_{2}\left(r_{1}\left(q_{1}^{S A}\right)-w_{1}\left(\theta q_{1}^{S A}+L_{1}^{S A}\left(q_{1}^{S A}\right)\right)\right.
$$

The marginal (country 2) output distortions from SA are captured by the transfer pricing term, $\Delta$, 
which is positive and hence favors SA. The latter two terms in (12) describe the marginal (country 2) output distortions from FA. The first FA-term reflects the ability of the firm to have its country 2 profits taxed at $t_{1}$ by selling nothing in country 2 . Under SA its country 2 profits are always taxed at $t_{2}$. When $t_{2}>t_{1}$, this ability favors FA. The second FA-term reflects the ability of the firm to influence its marginal tax rate. Since $\lambda_{2}$ is negative (an increase in $q_{2}$ decreases the share of a firm's global income taxed at $t_{1}$ ), this term favors SA when $t_{2}>t_{1}$. A marginal decrease in $w_{1}$ strengthens both of the FA-distortion terms but the change in the second term is proportional to country 1 sales, which also increases as $w_{1}$ decreases. Thus, a significantly lower wage rate in country 1 (relative to country 2's wage rate) implies larger global taxable income taxed at the higher rate and thus can shift the preference of a firm that sells almost exclusively in country 1 from FA to SA. A similar comparison due to revenue function differences can also be performed using (12).

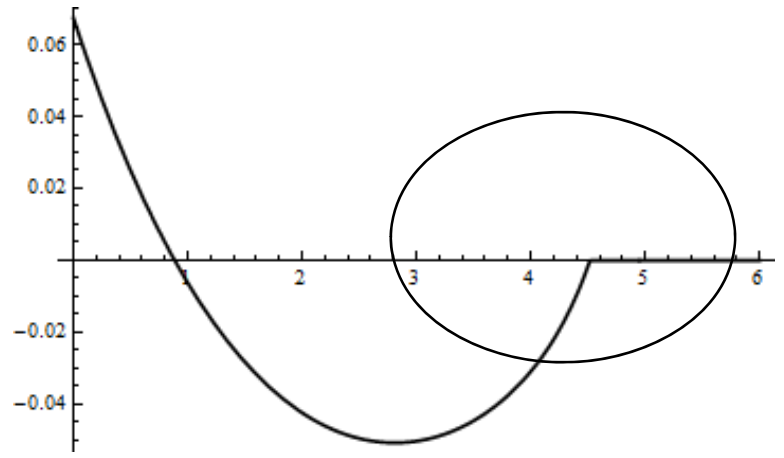

Figure 5: $\Pi^{S A}(\mu)-\Pi^{F A}(\mu)\left(w_{1}=1, t_{1}=.3, t_{2}=.5\right)$

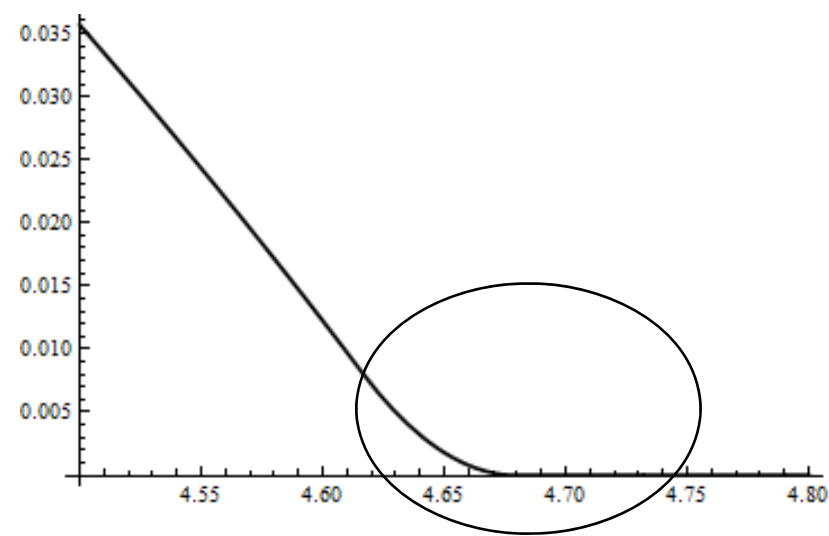

Figure 6: $\Pi^{S A}(\mu)-\Pi^{F A}(\mu)\left(w_{1}=.5, t_{1}=.3, t_{2}=.5\right)$

With these baseline results established for firms that operate near its first extensive margin, where it shuts down sales in one country, I now consider the selection patterns driven by a firm's intensive margins under country symmetry.

\subsubsection{Intensive margin effects with symmetric countries.}

A firm's indirect profits under FA and SA are identical when the countries have equal tax rates. Thus, some difference in tax rates is needed to generate a strict preference for one method 
over the other. To identify the intensive margin effects due solely to tax rate differences, I focus in this subsection on the effect of small tax rate differences with symmetric countries by calculating Taylor series expansions for $\Pi^{S A}\left(t_{1}, t_{2}, \cdot\right)$ and $\Pi^{F A}\left(t_{1}, t_{2}, \cdot\right)$. By focusing on small tax rate differences, no extensive margin effects are present. The role of country asymmetries and large tax rate differences will be analyzed in section 5 .

Theorem 3. Assume that at $t_{2}=t_{1}$, a firm with marginal cost of capital $\mu$ and productivity parameter $\theta$ produces strictly positive output in both countries under FA and SA. For $t_{2}$ sufficiently close to $t_{1}$, country symmetry and apportionment formula symmetry imply that

$$
\begin{aligned}
\Pi^{S A}\left(t_{1}, t_{2}, \cdot\right)-\Pi^{F A}\left(t_{1}, t_{2}, \cdot\right) & =\frac{\left(t_{2}-t_{1}\right)^{2}}{2} \cdot\left[\frac{-\mu^{2}}{2\left(1-t_{1}\right)^{3} r_{1}^{\prime \prime}} \cdot\left(K_{2}^{S A} / q_{2}^{S A}+1\right)^{2}+\frac{w_{2}}{2} \frac{\partial L_{2}^{S A}}{\partial t_{2}}+\frac{q_{2}^{S A}}{C^{\prime \prime}(0)}+\frac{2 \lambda_{1}^{2} \pi^{0^{2}}}{\left(1-t_{1}\right) r_{1}^{\prime \prime}}\right] \\
& +O\left(\left(t_{2}-t_{1}\right)^{3}\right)
\end{aligned}
$$

where all output and input quantities are calculated at $t_{2}=t_{1}$.

Eq. (13) is the second-order Taylor series expansion of $\Pi^{S A}-\Pi^{F A}$ near equal tax rates $\left(t_{1}, t_{1}\right)$. At equal tax rates, indirect profits are equal but so too are marginal indirect profits, i.e., $\partial \Pi^{S A}\left(t_{1}, t_{1}\right) / \partial t_{2}=\partial \Pi^{F A}\left(t_{1}, t_{1}\right) / \partial t_{2}$. The Envelope Theorem implies that marginal indirect profit under each method equals the negative of firm income taxed at the rate $t_{2}$. Equal marginal indirect profits thus mean that country 2's tax base is the same under FA and SA at equal tax rates. Therefore, a firm's choice between FA and SA when $t_{1}$ and $t_{2}$ are similar will be determined by how a change in $t_{2}$ affects the firm's taxable income in country 2 . This difference in marginal taxable income corresponds to the difference between $\partial^{2} \Pi^{S A}\left(t_{1}, t_{1}\right) / \partial t_{2}^{2}$ and $\partial^{2} \Pi^{F A}\left(t_{1}, t_{1}\right) / \partial t_{2}^{2}$. Both second derivatives are non-negative so that differences in the convexity of the firm's indirect profit functions with respect to $t_{2}$ will account for a firm's choice between FA and SA. 
The bracketed term in (13) equals $\partial^{2} \Pi^{S A}\left(t_{1}, t_{1}\right) / \partial t_{2}^{2}-\partial^{2} \Pi^{F A}\left(t_{1}, t_{1}\right) / \partial t_{2}^{2}$. Denote this term by $\Gamma\left(\mu, \theta ; t_{1}\right)$. It shows that a change in $t_{2}$ distorts country 2 's tax base in three ways: through an output distortion (due to the indirect effect of a change of $t_{2}$ on marginal indirect profit via $q_{1}$ and $q_{2}$ ), a conditional factor demand distortion (due to the indirect effect of a change of $t_{2}$ via the conditional factor demands), and an income-shifting distortion (due to the direct effect of a change in $t_{2}$ ). The first term in $\Gamma$ is positive and represents the difference in country 2 output distortions between FA and SA. For both FA and SA, a higher tax rate in country 2 lowers country 2 output which in turn increases marginal profit. However, the output distortion under SA is twice as large as the output distortion under FA as the amount of total income shifted under SA depends only on country 2 production while under FA the firm can use both country 1 and country 2 output to shift income.

The second term of $\Gamma$ represents the difference in the conditional labor demand distortions under FA and SA. The conditional labor demand distortions are positive, since an increase in $t_{2}$ gives firms the incentive to substitute labor for capital, and under the assumption of constant returns to scale in final good production they are larger under SA. The larger conditional labor demand distortion under SA arises for three reasons. First, the effect of $t_{2}$ on a firm's effective tax rate under FA is reduced by $1-\lambda$ relative to SA due to the apportionment formula. This effect is important because the conditional labor demand distortions measure the after-tax effect of a change in $t_{2}$. Second, with FA $t_{2}$ also affects a firm's capital-labor mix in both countries as it changes the after-tax wage rate. But the effect in each country is reduced by $1-\lambda$ since what matters to a firm is the after-tax wage rate, $w_{i}(1-T)$, which is only partially determined by $t_{2}$. Third, under SA $t_{2}$ only affects taxable income through country 2 labor costs while under FA $t_{2}$ affects taxable income, now $\pi^{0}$, through country 1 and country 2 labor costs. The proof of Theorem 3 in the appendix shows under country and formula symmetry and equal tax rates that $\partial L_{2}^{S A} / \partial t_{2}=\partial L_{1}^{F A} / \partial t_{2}+\partial L_{2}^{F A} / \partial t_{2}$. Thus, the aggregate conditional labor demand 
distortions on the tax base under FA equal the conditional labor demand distortions on country 2 taxable income under SA while the effect on the tax rate under FA is still reduced by $1-\lambda$ (which equals $1 / 2$ at equal tax rates).

The third and fourth terms of $\Gamma$ represent the difference in the (unit) income-shifting effects under FA and SA. Under SA, the income-shifting effect is positive. Recall from (2) that $\Delta$ is the after-tax profit earned from income-shifting per unit of country 2 output. At equal tax rates, $\partial^{2} \Delta / \partial t_{2}^{2}=1 / C^{\prime \prime}(0)$. As a result, the optimal amount of income shifted per unit of country 2 output is increasing at an increasing rate as $\left|t_{2}-t_{1}\right|$ increases. The income-shifting effect under FA is also positive (but is subtracted from the SA effect) as the income-shifting opportunities under FA increase with $\left|t_{2}-t_{1}\right|$ just as they do under SA. Note that its magnitude depends on how the apportionment formula varies with sales in each country.

Since the output and conditional labor demand distortions created by a change in $t_{2}$ always favor SA, the only way for a change in $t_{2}$ to generate higher profit under FA is if the apportionment formula generates a larger income-shifting effect. As $\mu$ goes to zero, the output and the conditional labor demand distortions go to zero because in the limit both tax methods are pure profit taxes at equal tax rates.

Corollary 1. There exists $\tilde{\mu}>0$ such that a firm with marginal cost of capital $\mu \in(0, \tilde{\mu})$ prefers FA over SA if, and only if, FA induces a larger income-shifting distortion. Corollary 1 states that for the firms with very low marginal costs of capital, their preferred tax method will be determined by the income-shifting distortion. Notice that the magnitude of the income-shifting distortion from FA is proportional to $\lambda_{1}$, the rate at which a firm's global income taxable in country 1 changes as country 1 output increases. Consider how $\lambda_{1}$ differs between an output formula and a sales-only formula. With symmetric countries and equal tax rates, $\lambda_{1}=1 / 4 q_{2}$ under an output formula while $\lambda_{1}=\left(1 / 4 q_{2}\right) \cdot\left(r_{2}^{\prime} / p_{2}\right)<1 / 4 q_{2}$ under a sales-only 
formula since marginal revenue is less than price at strictly positive quantities. ${ }^{12}$ Thus, (13) implies that firms with a low marginal cost of capital have a stronger incentive to prefer SA over a sales-only formula than over a quantity formula.

Figure 7 illustrates $\Gamma(\mu)$ with a sales-only formula under the same assumptions used for Figure 1. Since positive values favor SA, firms with marginal costs of capital below approximately 1.4 prefer SA while firms with marginal costs of capital above 1.4 prefer FA. With an output formula, instead of a sales-only formula, the analog to Figure 4 would show that all firms prefer FA. This change is consistent with the fact that an output formula generates stronger income-shifting distortions when $\mu$ is small.

Comparing Figures 1 and 7 also illustrates the importance of analyzing a firm's preferences near its extensive margins separately from the effect of its intensive margins. When $t_{2}=t_{1}, \mu_{1}^{S A}=\mu_{2}^{S A}=\mu_{1}^{F A}=\mu_{2}^{F A}$ so the extensive margin effect does not exist. That is, the extensive margin effect only materializes when $t_{2} \neq t_{1}$. As $t_{1}-t_{2}$ decreases below zero, the extensive

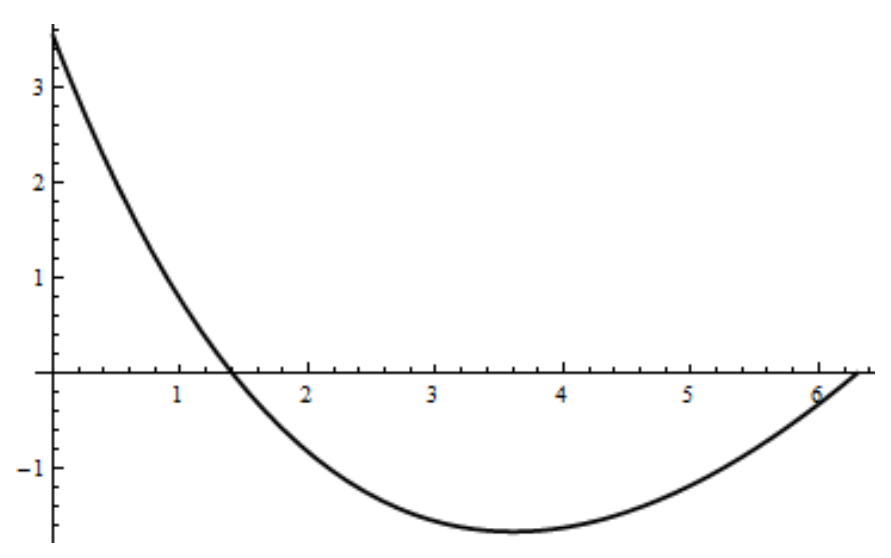

Figure 7: $\Gamma(\mu)$ for small tax differentials

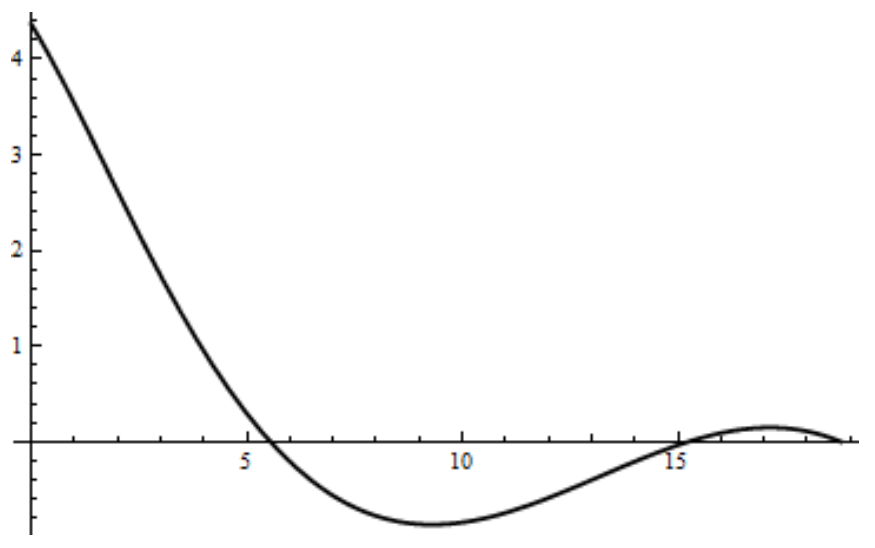

Figure 8: $\Gamma(\theta)$ for small tax differentials

margin effect seen for high- $\mu$ firms in Figure 3 arises. Combining the intensive margin effects of

\footnotetext{
${ }^{12}$ One could also write the expressions for $\lambda_{1}$ in terms of $q_{1}$ as all sales quantities are equal under country symmetry and equal tax rates.
} 
Theorem 3 with the extensive margin effects of Theorem 1 implies that, for the Figure 7 example with $t_{2}<t_{1}$, both low- $\mu$ and high- $\mu$ firms can prefer SA while medium- $\mu$ firms can prefer FA. Thus, the preferred firm method can vary non-monotonically with respect to $\mu$. This potential for non-monotonic firm choice calls into question empirical identification strategies that rely on the tax method choices of firms as in Mintz and Smart (2004).

Figure 8 illustrates the intensive margin incentives a firm faces given a small tax differential with a sales-only formula under the same assumptions used for Figure 7 but now as a function of $\theta$ and with $\mu=.1$. Note that the net output distortion is a constant in $\theta$ when revenues in each country are quadratic. Thus, the only intensive margin variation in firm profits under FA and SA (at equal tax rates) must come from the income-shifting and the conditional labor demand distortions. Second, one can see that the non-monotonic preferences of SA over FA can be generated solely by intensive margin incentives. Introducing the extensive margin effects when $t_{2}<t_{1}$ would further increase firm profit under SA for values of $\theta$ close to the country 1 extensive margin.

Eq. (13) also implies that if the intensive margin incentives support SA, they should do so for firms with low marginal costs of capital. With quadratic revenue functions and the production function used in the figures,

$$
\partial \Gamma / \partial \mu=\frac{2 \mu}{\left(1-t_{1}\right)^{3}}-\frac{1}{2\left(1-t_{1}\right)}+\frac{8 \mu \lambda_{1}^{2} \pi^{0}}{\left(1-t_{1}\right)^{3}}+\frac{2 \lambda_{1}\left(\pi^{0}\right)^{2} \lambda_{11}}{\left(1-t_{1}\right)^{2}} .
$$

The last term in (14) reveals that a firm's choice between FA and SA with respect to $\mu$ can depend on whether $\lambda(\cdot, \cdot)$ is concave or convex in $q_{1}$. (For a symmetric formula, if $\lambda(\cdot, \cdot)$ is concave in $q_{1}$ it must be convex in $q_{2}$ and vice versa.) When $\mu$ is close to zero, $\Gamma$ will be decreasing in $\mu$ as long as $\lambda(\cdot, \cdot)$ is not too convex in $q_{1}$. For both the output and the sales-only formulas, $\lambda(\cdot, \cdot)$ is strictly concave which means any profit advantage SA has at $\mu=0$ will initially diminish as $\mu$ increases. 


\section{Tax revenues.}

I now turn to the issue of how a firm's optimal choice affects tax revenues in each country under the assumptions of country symmetry and formula symmetry.

The tax revenue collected by country 1 from a firm that elects SA equals

$$
T R_{1}^{S A}\left(t_{1}, t_{2}\right)=t_{1}\left[r_{1}\left(q_{1}^{S A}\right)-w_{1}\left(L_{1}^{S A}\left(q_{1}^{S A}, t_{1}\right)+\theta q_{1}^{S A}\right)+\left(C^{\prime}\right)^{-1}\left(t_{2}-t_{1}\right) q_{2}^{S A}\right]
$$

while the tax revenue collected by country 1 from a firm that elects FA equals

$$
T R_{1}^{F A}\left(t_{1}, t_{2}\right)=\lambda\left(q_{1}^{F A}, q_{2}^{F A}\right) t_{1} \pi^{0}\left(q_{1}^{F A}, q_{2}^{F A}\right) .
$$

The formulas for country 2's tax revenues are analogous and can be found in the proof of Theorem 4 as (A.25) and (A.26). Eqs. (15) and (16) indicate that all three tax base distortions (output, conditional labor demand, and income-shifting) can influence each country's tax revenues through the tax method choice each firm makes. Because each firm's preference under country and formula asymmetry for small tax differences is determined solely by tax base distortions, one would expect the countries to have opposing preferences and that the firm's choice would favor the low tax rate country. To substantiate this intuition for firms on the intensive margin, I adopt a similar approach to that found in section 3.

Beginning with equal tax rates, note that a country's tax revenues under both methods are identical. Since $t_{2}$ does not affect $q_{1}^{S A}$ or $L_{1}^{S A}, \partial T R_{1}^{S A}\left(t_{1}, t_{1}\right) / \partial t_{2}=t_{1} \cdot q_{2}^{S A} / C^{\prime \prime}(0)$. That is, on the margin, a change in $t_{2}$ only affects country 1's tax revenues through its effect on a firm's transfer price, i.e., through the income-shifting distortion. Using Theorem 3 one can also write

$$
\partial T R_{1}^{S A}\left(t_{1}, t_{1}\right) / \partial t_{2}=t_{1}\left[\frac{\partial^{2} \Pi^{S A}}{\partial t_{2}^{2}}+\frac{\mu^{2}\left(1+K_{2}^{S A} / q_{2}^{S A}\right)^{2}}{\left(1-t_{1}\right)^{3} r_{2}^{\prime \prime}}-w_{2} \cdot \frac{\partial L_{2}^{S A}}{\partial t_{2}}\right]
$$

where the bracketed term in (17) represents the income-shifting distortion as the country 2 tax base distortion under SA from a change in $t_{2}$ minus the output and conditional labor demand distortions. In a similar fashion, (16) implies that $\partial T R_{1}^{F A}\left(t_{1}, t_{1}\right) / \partial t_{2}=d\left(\lambda \pi^{0}\right) / d t_{2}$ where $\partial^{2} \Pi^{F A} / \partial t_{2}^{2}=d\left(\lambda \pi^{0}\right) / d t_{2}-d \pi^{0} / d t_{2}$ (see (A.8) in the proof of Theorem 3$)$. Thus, the effect of a change in $t_{2}$ on country 1 's tax revenues under FA equals the country 2 tax base distortion plus 
the effect on a firm's global tax base, $\pi^{0}$, which includes both an output distortion and a conditional labor demand distortion. In the proof of Theorem 4, I show that the global tax base effect exactly offsets the output and conditional labor demand distortions in (17) so that country 1 's ranking of FA and SA depend only on a firm's ranking and the sign of $t_{2}-t_{1}$. As a result, for small tax rate differences country 1 will prefer the same method that a firm prefers when country 1 has the lower tax rate and it will prefer the opposite method a firm prefers when country 1 has the higher tax rate. Country 2's preference is the exact opposite of country 1's for any set of tax rates since when country 1 has the lower tax rate, country 2 has the higher tax rate.

Theorem 4. Assume that at $t_{2}=t_{1}$, a firm with marginal cost of capital $\mu$ and productivity parameter $\theta$ produces strictly positive output in both countries. Then country symmetry and apportionment formula symmetry imply that

$$
T R_{1}^{S A}\left(t_{1}, t_{2}\right)-T R_{1}^{F A}\left(t_{1}, t_{2}\right)=t_{1}\left(t_{2}-t_{1}\right)\left(\frac{\partial^{2} \Pi^{S A}\left(t_{1}, t_{1}\right)}{\partial t_{2}^{2}}-\frac{\partial^{2} \Pi^{F A}\left(t_{1}, t_{1}\right)}{\partial t_{2}^{2}}\right)+O\left(\left(t_{2}-t_{1}\right)^{2}\right)
$$

and

$$
T R_{2}^{S A}\left(t_{1}, t_{2}\right)-T R_{2}^{F A}\left(t_{1}, t_{2}\right)=t_{2}\left(t_{1}-t_{2}\right)\left(\frac{\partial^{2} \Pi^{S A}\left(t_{1}, t_{1}\right)}{\partial t_{2}^{2}}-\frac{\partial^{2} \Pi^{F A}\left(t_{1}, t_{1}\right)}{\partial t_{2}^{2}}\right)+O\left(\left(t_{2}-t_{1}\right)^{2}\right) .
$$

Figures 1 and 2 illustrate the relationship described in Theorem 4 between the profit differential that drives each firm's choice and the tax revenue differential that determines whether the effect of a firm's choice on each country's tax revenues is positive or negative. The preference alignment patterns also exist with respect to variation in $\theta$. Thus, the intensive margin effects imply that if one country collects more tax revenues from a firm with the ability to choose between SA and FA, the other country will collect fewer tax revenues.

The extensive margin effects of choice can undermine the perfect alignment of the preferences of a firm with the preferences of the low tax rate country. When country 2 has the lower tax rate, firms with high marginal costs of capital prefer SA as does country 2. For hightax country 1 , if there exists a set of firms (below but close to the extensive margin) who prefer FA, the preferences of these firms will be aligned with country 1's preferences (Figures 3 and 4 
provide an example of this possibility). ${ }^{13}$

\section{Country asymmetries.}

Up to this point, the analysis of intensive margin effects has focused on the case of symmetric countries. (The extensive margin analysis required no symmetry assumptions.) To illustrate the effect of country asymmetries on firm choice, I now consider the effect of small tax rate differences in the presence of small wage differences. Using the same Taylor series approach, recall that indirect profits under SA and FA are identical regardless of any difference in wage rates, that is, $\Pi^{S A}\left(t_{1}, t_{1}, w_{1}, w_{2}\right)=\Pi^{F A}\left(t_{1}, t_{1}, w_{1}, w_{2}\right)$. It is also the case that at equal tax rates $\partial \Pi^{S A} / \partial w_{2}=\partial \Pi^{F A} / \partial w_{2}$. At equal tax rates and equal wage rates, $\partial \Pi^{S A} / \partial t_{2}=\partial \Pi^{F A} / \partial t_{2}$ and $\partial^{2} \Pi^{S A} / \partial w_{2}^{2}=\partial^{2} \Pi^{F A} / \partial w_{2}^{2}$. Thus, the second-order Taylor series expansion of $\Pi^{S A}-\Pi^{F A}$ is

$$
\Pi^{S A}\left(t_{1}, t_{2}, w_{1}, w_{2}\right)-\Pi^{F A}\left(t_{1}, t_{2}, w_{1}, w_{2}\right)=\frac{\left(t_{1}-t_{2}\right)^{2}}{2} \cdot \frac{\partial^{2}\left(\Pi^{S A}-\Pi^{F A}\right)}{\partial t_{2}^{2}}+\left(t_{2}-t_{1}\right)\left(w_{2}-w_{1}\right) \frac{\partial^{2}\left(\Pi^{S A}-\Pi^{F A}\right)}{\partial w_{2} \partial t_{2}}
$$

where all derivatives are calculated at $\left(t_{1}, t_{1}, w_{1}, w_{1}\right)$. Note that the sign of the new cross-effect term will depend on both the tax rate differential and the wage rate differential. Calculations similar to those for Theorem 3 imply that at $\left(t_{1}, t_{1}, w_{1}, w_{1}\right)$

$$
\frac{\partial^{2}\left(\Pi^{S A}-\Pi^{F A}\right)}{\partial w_{2} \partial t_{2}}=-\frac{\mu\left(\mathrm{K}_{2}^{S A} / q_{2}^{S A}+1\right) \mathrm{L}_{2}^{S A} / q_{2}^{S A}}{\left(1-t_{2}\right) r_{2}^{\prime \prime}}+\frac{1}{2}\left(L_{2}^{S A}+w_{2} \frac{\partial L_{2}^{S A}}{\partial w_{2}}\right)+\frac{\lambda_{2}}{2} \cdot \pi^{0} \cdot L_{2}^{S A} / q_{2}^{S A} .
$$

As in (13), the first term on the right-hand side of (21) represents the net output distortion caused by a change in $w_{2}$ and $t_{2}$. It is positive reflecting the fact that the linkage effect induces larger output distortions under SA. The second term on the right-hand side of (21) represents the net

\footnotetext{
${ }^{13}$ What looks like a discontinuous jump in country 1 tax revenues in Figure 3 is in fact not discontinuous. The apparent jump corresponds to a small range of values of $\mu$ in which a firm sells a small amount in country 1 under FA but nothing under SA. For values of $\mu$ in this range country 1 tax revenues from SA are negative since the firm is generating zero revenues in country 1 and is shifting some income to country 2 . In practice, firms often have other domestic operations that can mask such extreme income-shifting so I do not rule out the possibility of negative tax revenues. Prohibiting negative tax revenues would reduce, but not eliminate this extensive margin effect.
} 
distortion in the conditional demand for labor in country 2. This term is negative if the conditional demand for labor in country 2 for final good production by a firm is inelastic and is positive if it is elastic. The last term represents the income-shifting distortion under FA and is negative since more country 2 output results in less income being taxed in country 1 . There is no income-shifting distortion under SA in (21) (due to a change in $w_{2}$ ) since the only effect of wage rates on a firm's transfer price is through $w_{1}$ as it determines the arm's-length price. The sign of $\partial^{2}\left(\Pi^{S A}-\Pi^{F A}\right) / \partial w_{2} \partial t_{2}$ can be positive or negative depending on the apportionment formula being used just as one saw with (13). Figure 9 illustrates the potential effect of a change in the wage rate differential. The thin line corresponds to $\Pi^{S A}(\mu)-\Pi^{F A}(\mu)$ on the intensive margin
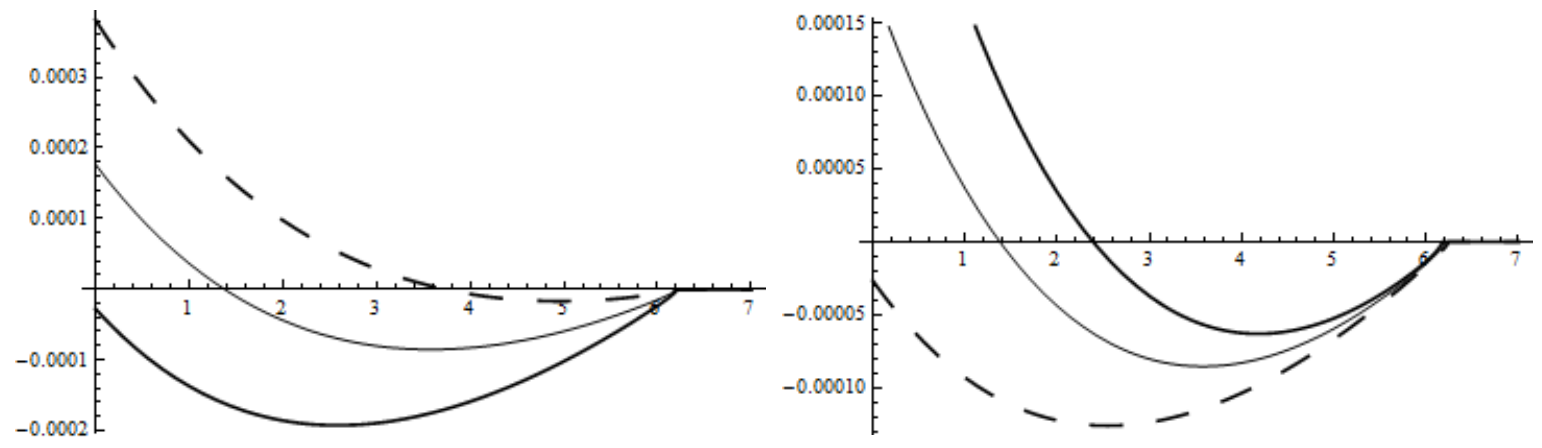

Figure 9: $\Pi^{S A}(\mu)-\Pi^{F A}(\mu)$ for $w_{1}=1, t_{1}=.3$, Figure 10: $\Pi^{S A}(\mu)-\Pi^{F A}(\mu)$ for $w_{1}=1, a_{1}=20$, and $t_{2}=.31$ for $w_{2}=1$ (thin solid line), $w_{2}=t_{1}=.3$, and $t_{2}=.31$ for $w_{2}=1$ and $a_{2}=20$ (thin .995 (thick solid line), and $w_{2}=1.005$ (dashed line). solid line), $w_{2}=.995$ and $a_{2}=19.9$ (thick solid line), and $w_{2}=1.005$ and $a_{2}=20.1$ (dashed line).

when $w_{1}=w_{2}=1, t_{1}=.3$, and $t_{2}=.31$. The additional cross-partial term, (21), that captures the effect of a wage rate differential is always positive for the example. Thus, when country 1 has the lower tax rate we should expect to see $\Pi^{S A}-\Pi^{F A}$ decrease for $w_{1}>w_{2}$ and increase for $w_{1}<w_{2}$. This is observed in Figure 9 in which the thick line corresponds to $w_{1}=1$ and $w_{2}=.995$ while the dashed line corresponds to $w_{1}=1$ and $w_{2}=1.005$. Thus, a higher wage rate in a low tax rate upstream country biases a firm's decision toward FA while a lower wage rate in a low tax rate upstream country biases the firm's decision towards SA. If country 2 had the lower tax 
rate, the positions of the thick line (corresponding to a higher wage rate in country 1) and the dashed line (corresponding to a lower wage rate in country 1) would be reversed. The thick line also shows that relatively small wage rate differences can dominate the tax rate differential effects.

A similar analysis can be conducted with respect to changes in demand. ${ }^{14}$ Specifically, if one assumes linear inverse demand in country $i$ of $P\left(q_{i}\right)=a_{i}-q_{i}$, one can analyze the effects of differences between the choke-off prices $a_{1}$ and $a_{2}$ using the same methods used for wage rate differentials. Demand asymmetries work in the opposite direction of wage rate asymmetries. Depending on the magnitudes of both the wage and demand differentials, these countervailing effects could result in the difference in firm profit being determined primarily by the tax rate differences. Figure 10 illustrates this possibility. Each line corresponds to the difference in firm profits, $\Pi^{S A}(\mu)-\Pi^{F A}(\mu)$. The thin solid line comes from the baseline case in which $w_{1}=w_{2}=1$ and $a_{1}=a_{2}=20$. The thick solid line illustrates the profit differences when the downstream country has a smaller wage rate and smaller demand while the dashed line illustrates the profit differences when the downstream country has a larger wage rate and larger demand. The wage rate and demand differences in each case are $.5 \%$ of the baseline values. In this example, the demand differences dominate the wage rate differences but still produce a profit differential profile that is qualitatively similar to the one predicted by Theorem 3 that considers only tax rate differences between countries. Thus, in contrast with Figure 9, the combination of higher wages and larger demand in the higher tax-rate downstream country encourages more firms to choose FA.

Finally country asymmetries can alter the countries' preferences over SA and FA. In particular, country asymmetries can create misalignment of preferences between some firms and the low tax rate country and alignment of preferences between some firms and the high tax rate

${ }^{14}$ Details are available from the author on request. 
country. The relationship between each country's tax revenues and firm profits in the presence of country asymmetries is described in Theorem 5. To state this theorem, the second-order Taylor series expansion of $\Pi^{S A}-\Pi^{F A}$ around equal tax rates, wage rates, and demand parameters is $\Pi^{S A}\left(t_{1}, t_{2}, w_{1}, w_{2}, a_{1}, a_{2}\right)-\Pi^{F A}\left(t_{1}, t_{2}, w_{1}, w_{2}, a_{1}, a_{2}\right)$
$\approx \frac{\left(t_{1}-t_{2}\right)^{2}}{2} \cdot \frac{\partial^{2}\left(\Pi^{S A}-\Pi^{F A}\right)}{\partial t_{2}^{2}}+\left(t_{2}-t_{1}\right)\left(w_{2}-w_{1}\right) \frac{\partial^{2}\left(\Pi^{S A}-\Pi^{F A}\right)}{\partial w_{2} \partial t_{2}}+\left(t_{2}-t_{1}\right)\left(a_{2}-a_{1}\right) \frac{\partial^{2}\left(\Pi^{S A}-\Pi^{F A}\right)}{\partial a_{2} \partial t_{2}}$

where all the derivatives are evaluated at $t_{2}=t_{1}, w_{2}=w_{1}$, and $a_{2}=a_{1}$. Denote the right-hand side of (22) by $\Delta \Pi$.

Theorem 5. Assume that at $t_{2}=t_{1}, w_{2}=w_{1}$, and $a_{2}=a_{1}$, a firm with marginal cost of capital $\mu$ and productivity parameter $\theta$ produces strictly positive output in both countries. Then apportionment formula symmetry implies that

$$
\begin{aligned}
& T R_{1}^{S A}\left(t_{1}, t_{2}, w_{1}, w_{2}, a_{1}, a_{2}\right)-T R_{1}^{F A}\left(t_{1}, t_{2}, w_{1}, w_{2}, a_{1}, a_{2}\right) \\
& \quad=\frac{t_{1}}{t_{2}-t_{1}}\left(\Delta \Pi+\frac{\left(t_{2}-t_{1}\right)^{2}}{2} \cdot\left[\frac{\partial^{2} \Pi^{S A}}{\partial t_{2}^{2}}-\frac{\partial^{2} \Pi^{F A}}{\partial t_{2}^{2}}\right]\right)+O\left(\left(t_{2}-t_{1}\right)^{2}\right)
\end{aligned}
$$

and

$$
\begin{aligned}
& T R_{2}^{S A}\left(t_{1}, t_{2}, w_{1}, w_{2}, a_{1}, a_{2}\right)-T R_{2}^{F A}\left(t_{1}, t_{2}, w_{1}, w_{2}, a_{1}, a_{2}\right) \\
& \quad=\frac{-t_{2}}{t_{2}-t_{1}}\left(\Delta \Pi+\frac{\left(t_{2}-t_{1}\right)^{2}}{2} \cdot\left[\frac{\partial^{2} \Pi^{S A}}{\partial t_{2}^{2}}-\frac{\partial^{2} \Pi^{F A}}{\partial t_{2}^{2}}\right]\right)+O\left(\left(t_{2}-t_{1}\right)^{2}\right)
\end{aligned}
$$

where all derivatives are evaluated at $t_{2}=t_{1}, w_{2}=w_{1}$, and $a_{2}=a_{1}$.

Theorem 5 is the generalization of Theorem 4 that allows for small country asymmetries. ${ }^{15}$ The terms in large parentheses in (23) and (24) are identical. The difference between the equations is in the coefficients. Notice that the coefficient, $t_{1} /\left(t_{2}-t_{1}\right)$ and $-t_{2} /\left(t_{2}-t_{1}\right)$, must have opposite signs. This means the countries must have opposing preferences when the asymmetries are small. The term in large parentheses depends on the difference in firm profit, $\Delta \Pi$, which now depends on the marginal tax base effects with respect to changes in $t_{2}$, and a term that reflects the second-order changes in firm profit due solely to tax base differences. As explained in section 4, this term captures the effect on firm profits from the change in the tax

\footnotetext{
${ }^{15}$ The proof follows the same arguments as those used to prove Theorem 4. Details are available on request.
} 
base with respect to a change in $t_{2}$. In the absence of wage rate and demand asymmetries, this term is equal to $\Delta \Pi$. With wage rate or demand asymmetries, it is just one component of the difference in firm profit under FA and SA. Since it is possible for $\Delta \Pi$ and $\partial^{2}\left(\Pi^{S A}-\Pi^{F A}\right) / \partial t_{2}^{2}$ to have different signs, the scope arises for a country to have the same preferences as some firms and the opposite preferences for others. Figure 11 illustrates this possibility for country 1 tax revenues when $t_{1}=.3, t_{2}=.31, w_{1}=1, w_{2}=1.005, a_{1}=20$, and $a_{2}=20.1$. While all firm types prefer FA, country 1 prefers that firms with a marginal cost of capital below approximately 6 choose SA and firms with marginal cost of capital above .6 choose FA. Without the wage rate and demand differences, country 1's preference would always agree with each firm's preference.

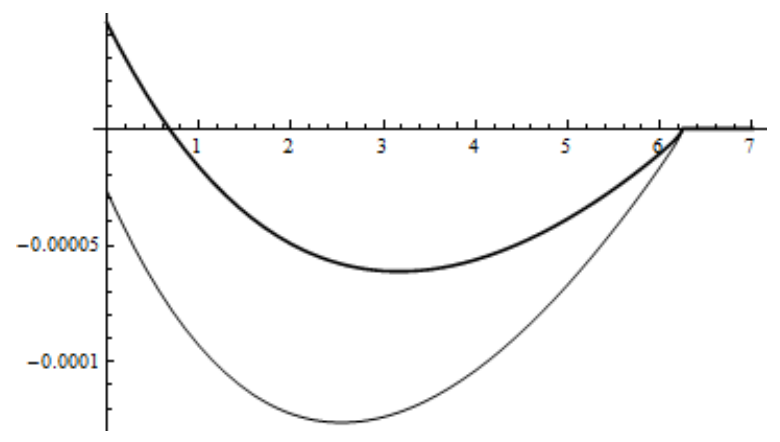

Figure 11: $\Pi^{S A}(\mu)-\Pi^{F A}(\mu)$ (thin line) and $\boldsymbol{T R}_{\mathbf{J}}^{\boldsymbol{S A}}(\boldsymbol{\mu})-\boldsymbol{T R}_{\mathbf{1}}^{\boldsymbol{R A}}(\boldsymbol{\mu})$ (thick line) for $t_{1}=.3, t_{2}=.31$, $w_{1}=1, w_{2}=1.005, a_{1}=20$, and $a_{2}=20.1$.

Country 2 has the opposite preference which means that it concurs with the decision of firms with $\mu<.6$ to choose FA.

\section{Pareto improving choice?}

Is it possible for a policy of choice to benefit both countries as well as the firm? In the case of (nearly) symmetric countries and similar tax rates, Theorem 5 implies it is not. However, Figures 3 and 4 show that with sufficient country asymmetries and/or sufficient tax rate differences Pareto-improving choice can result with certain firm types. Thus, the answer to this question depends on two additional factors we have not yet considered: the cdf of firm types, $\Phi(\mu, \theta)$, and the baseline method against which choice is to be compared. At the aggregate level, as long as each country's preferred method aligns with the preferred method of enough 
firms, firm choice could increase each country's aggregate tax revenues. For the example in Figure 4, this would require that enough mass be placed on firms with values of $\mu$ between 1 and 1.4. However, in order for a policy of choice to increase tax revenues in both countries the alternative policy would have to be one that requires all firms to use FA. If the comparison was between mandating SA or letting firms choose, they would choose SA and the countries would experience no change in tax revenues.

The reason that both countries can agree with a firm's choice can be seen in Figure 4 where firms with values of $\mu$ between 1 and 1.4 prefer SA. Recall that $\Pi^{F A}$ and $\Pi^{S A}$ are both decreasing in $\mu$. The issue of firm choice is which indirect profit falls faster as $\mu$ increases. In the example, $\Pi^{S A}$ is falling faster which means that country 1 views SA less favorably while country 2 views SA more favorably. If the countries were identical, the change in their tax revenues would offset each other. However, with a lower wage rate, country 2's tax base falls slower than country 1's tax base. Thus, the countries relative preferences for FA and SA do not change proportionately. It is this non-proportionate change in tax bases that creates the opportunity for choice to be Pareto-improving with some firm types.

The other possible reason that choice can be Pareto-improving emerges if one generalizes the model to allow some firms to have intermediate good production in country 1 and some to have intermediate good production in country 2 . This change requires no new firm-specific analysis and can be accommodated by introducing a type distribution conditional on where a firm's intermediate good production is located. Let $\Phi_{1}(\mu, \theta)$ and $\Phi_{2}(\mu, \theta)$ denote the cumulative distribution functions for firms with intermediate good production in country 1 and country 2, respectively. Theorem 5 applies separately to the firms with intermediate good production in the same country. As long as $\Phi_{1}$ and $\Phi_{2}$ are different distributions, additional scope for Paretoimproving choice exists. 


\section{Summary and conclusions.}

SA and FA represent two rather distinct methods for allocating a multinational's global operating income across each country in which the firm operates in order to calculate national tax liabilities. In this paper, I have focused on how these two methods generate different output, income-shifting, and conditional labor demand distortions and how these distortions influence a firm's preference between these two methods for the case in which the apportionment formula depends solely on final good quantities. Theorem 3 reveals that, when symmetric countries have similar tax rates, the output and conditional labor demand distortions on the intensive margin always favor SA while the (intensive margin) profit-shifting distortions can favor either method. At the same time tax rate differences create extensive margin effects in which firms operating near the extensive margins strictly prefer SA to FA when the downstream country has the lower tax rate. Theorem 4 then shows that the intensive margin incentives align firm preferences and country preferences for the country with the lower tax rate and misalign firm and country preferences for the country with the higher tax rate. Thus, a policy of choice in a symmetric environment will create intensive margin incentives that increase tax revenues in the lower tax rate country and decrease tax revenues in the higher tax rate country. Extensive margin incentives as well as country asymmetries can introduce some misalignment of preferences between the firm and the lower tax rate country and can introduce some alignment of preferences between the firm and the higher tax rate country. With sufficient country and/or tax rate differences this partial alignment/misalignment can result in choice increasing the tax revenues in each country. Thus, Theorem 5 tells us that the more similar countries are, the less likely it is that both countries would favor a policy of choice.

In future research, it will be important to determine whether similar results emerge for apportionment formulas that use factor shares as well as output shares. As noted above, introducing factor shares in apportionment formulas can create an incentive for firms to employ 
more capital and/or labor than they would need to meet output goals. It is also the case that evaluating the effects of choice using a more general welfare criterion would likely imply that the ratio of welfare gains in one country to welfare losses in another are sufficiently different to create the possibility of Pareto-improving choice. I leave these topics for future research. 


\section{References}

Bauer, C. and D. Langenmayr, 2013, Sorting into outsourcing: Are profits taxed at a gorilla's arm's length? Journal of International Economics 90: 326-336.

Eichner, T. and M. Runkel, 2008, Why the European Union should adopt formula apportionment with a sales factor. Scandinavian Journal of Economics 110: 567-589.

, 2011, Corporate income taxation of multinationals in a general equilibrium market. Journal of Public Economics 95: 723-733.

European Commission, 2011, Proposal for a Directive on a Common Consolidated Corporate Tax Base (CCCTB), COM (2011) 121/3, Brussels.

Gresik, T., 2010, Separate accounting vs. formula apportionment: A private information perspective. European Economic Review 54:133-149.

Gresik, T. and P. Osmundsen, 2008, Transfer pricing in vertically integrated industries, International Tax and Public Finance 15:231-255.

Mintz, J. and M. Smart, 2004, Income shifting, investment, and tax competition: theory and evidence from provincial taxation in Canada. Journal of Public Economics 88: 1149-1168. Nielsen, S., P. Raimondos-Møller, G. Schjelderup, 2003, Formula apportionment and transfer pricing under oligopolistic competition. Journal of Public Economic Theory 5: 417-436. ,2010, Company taxation and tax spillovers: Separate accounting versus formula apportionment. European Economic Review 54:121-132.

OECD, 2010, OECD transfer price guidelines for multinational enterprises and tax administrations, Paris. 


\section{Appendix}

Lemma 1. If the countries are symmetric and demand is sufficiently large, then $\mu_{1}^{S A}<\mu_{2}^{S A}$ if, and only if, $t_{1}>t_{2}$.

Proof of Lemma 1. An interior solution to a firm's profit-maximization problem under SA requires that $q_{1}^{S A}$ solve

$$
\left(1-t_{1}\right)\left(r_{1}^{\prime}\left(q_{1}\right)-w_{1}\left(\partial L_{1}^{S A} / \partial q_{1}+\theta\right)\right)-\mu\left(K_{1}^{S A} / q_{1}+1\right)=0
$$

and $q_{2}^{S A}$ solve

$$
\left(1-t_{2}\right)\left(r_{2}^{\prime}\left(q_{2}\right)-w_{2} \partial L_{2}^{S A} / \partial q_{2}-w_{1} \theta\right)+\Delta\left(t_{1}, t_{2}\right)-\mu\left(\partial K_{2}^{S A} / \partial q_{2}+1\right)=0 .
$$

Define $A V C_{i}\left(q_{i}, t_{i}, w_{i}, \mu\right)=\left(\left(1-t_{i}\right) w_{i} L_{i}^{S A}+\mu K_{i}^{S A}\right) / q_{i}$. Under constant returns to scale, $\left(1-t_{i}\right) w_{i} \partial L_{i}^{S A} / \partial q_{i}+\mu \partial K_{i}^{S A} / \partial q_{i}=A V C_{i}\left(q_{i}, t_{i}\right)$ and $L_{i}^{S A} / q_{i}, K_{i}^{S A} / q_{i}$, and $A V C_{i}$ are all positive, constant functions of $q_{i}$.

First note that

$$
\frac{\partial^{2} \pi^{S A}}{\partial q_{i}^{2}} \cdot \frac{\partial q_{i}^{S A}}{\partial \mu}=\frac{\partial K_{i}^{S A}}{\partial q_{i}}+1+\frac{\partial A V C_{i}\left(q_{i}, t_{i}, w_{i}, \mu\right)}{\partial \mu}
$$

and that, by the Envelope Theorem, $\partial A V C_{i} / \partial \mu=K_{i}^{S A} / q_{i}$. Thus, $\partial q_{i}^{S A} / \partial \mu<0$ so there exists $\mu_{i}^{S A}\left(t_{i}, w_{i}\right)>0$ such that $q_{i}^{S A}=0$ for all $\mu \geq \mu_{i}^{S A}$.

Second, note that under country symmetry $q_{1}^{S A}=q_{2}^{S A}$ when $t_{1}=t_{2}$. Thus, the sign of $\partial q_{2}^{S A} / \partial t_{2}$ can be used to compare $\mu_{1}^{S A}$ with $\mu_{2}^{S A}$. Differentiating (A.2) with respect to $t_{2}$ implies

$$
\frac{\partial^{2} \pi^{S A}}{\partial q_{2}^{2}} \cdot \frac{\partial q_{2}^{S A}}{\partial t_{2}}=\mu+A V C_{2}+\left(1-t_{2}\right) \frac{\partial A V C_{2}}{\partial t_{2}}-\Delta\left(t_{1}, t_{2}\right)-\left(1-t_{2}\right) \frac{\partial \Delta}{\partial t_{2}} .
$$

By the Envelope Theorem,

$$
A V C_{2}+\left(1-t_{2}\right) \partial A V C_{2} / \partial t_{2}=\left(1-t_{2}\right) w_{2} L_{2}^{S A} / q_{2}^{S A}+\mu K_{2}^{S A} / q_{2}^{S A}-\left(1-t_{2}\right) w_{2} L_{2}^{S A} / q_{2}^{S A}=\mu K_{2}^{S A} / q_{2}^{S A}>0 \text {. }
$$

To sign the remaining terms on the right-hand side of (A.3), define $\tilde{\Delta}\left(t_{1}, t_{2}\right)=\Delta\left(t_{1}, t_{2}\right)+\left(1-t_{2}\right) \partial \Delta\left(t_{1}, t_{2}\right) / \partial t_{2}$. Note that $\tilde{\Delta}\left(t_{1}, t_{1}\right)=0$ and $\partial \tilde{\Delta}\left(t_{1}, t_{2}\right) / \partial t_{2}=\left(1-t_{2}\right)\left(\left(C^{\prime}\right)^{-1}\right)^{\prime}\left(t_{2}-t_{1}\right)>0$ for all $t_{2}<1$ by the convexity of $C(\cdot)$. Thus, $\tilde{\Delta}\left(t_{1}, t_{2}\right)\left(t_{2}-t_{1}\right) \geq 0$ for all $t_{1}$ and $t_{2}$. 
If $t_{2}<t_{1}$, then $\tilde{\Delta}<0$ and $\partial q_{2}^{S A} / \partial t_{2}<0$ for all $t_{2}<t_{1}$. Thus, $q_{2}^{S A}>q_{1}^{S A}$ and $\mu_{1}^{S A}<\mu_{2}^{S A}$. If $t_{2}>t_{1}$, then $\tilde{\Delta}>0$ and the sign of $\partial q_{2}^{S A} / \partial t_{2}$ is indeterminate. For each $t_{1}>0$, there exists $\varepsilon>0$ such that for all $t_{2} \in\left(t_{1}, t_{1}+\varepsilon\right), \partial q_{2}^{S A} / \partial t_{2}<0$ and $q_{2}^{S A}$ will be strictly less than $q_{1}^{S A}$. However, $\tilde{\Delta}\left(t_{1}, t_{2}\right)$ is bounded above by $\tilde{\Delta}(0,1)$ which is finite while $\mu\left(K_{2}^{S A} / q_{2}^{S A}+1\right)>\mu$. Thus, there exists $\mu_{0}>0$ such that for all $\mu>\mu_{0}, \partial q_{2}^{S A} / \partial t_{2}<0$ for all $t_{2}>t_{1}$. If $\mu_{0}<\mu_{1}^{S A}$, then a firm will set $q_{2}^{S A}=0$ before setting $q_{1}^{S A}=0$, that is, $\mu_{2}^{S A}<\mu_{1}^{S A}$. While $\mu_{1}^{S A}$ is a function of demand in country $1, \mu_{0}$ is not. Thus, since $r_{1}^{\prime}(0)=p_{1}(0)$, which is assumed to be finite, there exists $\bar{k}>0$ such that for all $k>\bar{k}$, so that with country 1 demand $p_{1}\left(q_{1}\right)+k, \mu_{0}$ will be less than $\mu_{1}^{S A}$ for all $t_{2}>t_{1}$.

Q.E.D.

Lemma 2. If the countries are symmetric, then $\mu_{1}^{F A}<\mu_{2}^{F A}$ if, and only if, $t_{1}>t_{2}$.

Proof of Lemma 2. This proof proceeds in two steps. First, I will prove that $\left(t_{2}-t_{1}\right)\left(q_{2}-q_{1}\right) \geq 0$. Then I will show that $\left(t_{2}-t_{1}\right)\left(q_{2}-q_{1}\right)>0$ whenever $t_{2} \neq t_{1}$.

Step 1. Without loss of generality assume that $t_{2}>t_{1}$ and that $\pi^{F A}\left(q_{1}, q_{2}\right)$ is maximized at $\left(q_{1}^{*}, q_{2}^{*}\right)$ such that $0 \leq q_{1}^{*}<q_{2}^{*}$. I will show that these two assumptions lead to a contradiction.

First, note that $\pi^{0}\left(q_{1}^{*}, q_{2}^{*}\right)>0$ regardless of which quantity is larger, as otherwise $\pi^{F A}\left(q_{1}^{*}, q_{2}^{*}\right)$ would be strictly negative. Since $\pi^{F A}(0,0)=0,\left(q_{1}^{*}, q_{2}^{*}\right)$ cannot be profit-maximizing if it implies $\pi^{0}\left(q_{1}^{*}, q_{2}^{*}\right)<0$.

Next notice that

$$
\begin{aligned}
\pi^{F A}\left(q_{2}^{*}, q_{2}^{*}\right) \geq & \left(1-T\left(q_{2}^{*}, q_{2}^{*}\right)\left(r_{1}\left(q_{2}^{*}\right)+r_{2}\left(q_{2}^{*}\right)-w_{1} \theta\left(q_{2}^{*}+q_{2}^{*}\right)-w_{1} L_{1}^{F A}\left(q_{1}^{*}, q_{2}^{*}\right)-w_{2} L_{2}^{F A}\left(q_{1}^{*}, q_{2}^{*}\right)\right)\right. \\
& -\mu\left(K_{1}^{F A}\left(q_{1}^{*}, q_{2}^{*}\right)+K_{2}^{F A}\left(q_{1}^{*}, q_{2}^{*}\right)+q_{2}^{*}+q_{2}^{*}\right) \\
> & \left(1-T\left(q_{1}^{*}, q_{2}^{*}\right)\left(r_{1}\left(q_{2}^{*}\right)+r_{2}\left(q_{2}^{*}\right)-w_{1} \theta\left(q_{2}^{*}+q_{2}^{*}\right)-w_{1} L_{1}^{F A}\left(q_{1}^{*}, q_{2}^{*}\right)-w_{2} L_{2}^{F A}\left(q_{1}^{*}, q_{2}^{*}\right)\right)\right. \\
& -\mu\left(K_{1}^{F A}\left(q_{1}^{*}, q_{2}^{*}\right)+K_{2}^{F A}\left(q_{1}^{*}, q_{2}^{*}\right)+q_{2}^{*}+q_{2}^{*}\right)
\end{aligned}
$$

where the first inequality follows from the assumption that $\left(q_{1}^{*}, q_{2}^{*}\right)$ is optimal and the second inequality follows from the fact that $T\left(q_{1}^{*}, q_{2}^{*}\right)>T\left(q_{2}^{*}, q_{2}^{*}\right)$ because $t_{2}>t_{1}$ implies that reducing country 1 sales from $q_{2}^{*}$ to $q_{1}^{*}$ increases $T$.

Since $q_{2}^{*}>0$, it must be that $\partial \pi^{F A}\left(q_{1}^{*}, q_{2}^{*}\right) / \partial q_{2}=0$ or that 


$$
(1-T)\left(r_{2}^{\prime}\left(q_{2}^{*}\right)-w_{1} \theta\right)-\mu=A V C_{2}^{F A}\left(q_{1}^{*}, q_{2}^{*}\right)-\left(t_{2}-t_{1}\right) \lambda_{2} \pi^{0}>0
$$

Thus, for $T$ fixed, $(1-T)\left(r_{1}^{\prime}\left(q_{1}\right)-w_{1} \theta\right)-\mu>0$ for all $q_{1} \leq q_{2}^{*}$ when the countries are symmetric. This means that for all $q_{1} \leq q_{2}^{*}$,

$$
\left(1-T\left(q_{1}^{*}, q_{2}^{*}\right)\right) \int_{x=q_{1}}^{q_{2}^{*}}\left(r_{1}^{\prime}(x)-w_{1} \theta-\mu\right) d x \geq 0 .
$$

Inequality (A.5) in turn implies that the right-hand side of the second inequality in (A.4) is greater than or equal to $\pi^{F A}\left(q_{1}^{*}, q_{2}^{*}\right)$. Thus, combining (A.4) and (A.5) implies that $\left(q_{1}^{*}, q_{2}^{*}\right)$ cannot be profit-maximizing when $q_{1}^{*}<q_{2}^{*}$.

Step 2. Note that $\lambda_{1}\left(q_{2}^{*}, q_{2}^{*}\right)$ and $\lambda_{2}\left(q_{2}^{*}, q_{2}^{*}\right)$ must have opposite signs. Thus, $t_{2}>t_{1}$ implies $\partial \pi^{F A}\left(q_{2}^{*}, q_{2}^{*}\right) / \partial q_{1}>\partial \pi^{F A}\left(q_{2}^{*}, q_{2}^{*}\right) / \partial q_{2}$ which means $q_{1}^{*}>q_{2}^{*}$. A similar argument shows that $q_{1}^{*}<q_{2}^{*}$ when $t_{2}<t_{1}$.

Theorem 1. Assume that $\bar{\mu}_{1} \equiv \max \left\{\mu_{1}^{S A}, \mu_{1}^{F A}\right\}<\min \left\{\mu_{2}^{S A}, \mu_{2}^{F A}\right\} \equiv \underline{\mu}_{2}$. There exists $\hat{\mu}<\bar{\mu}_{1}$ such that a firm with marginal cost of capital $\mu \in\left(\hat{\mu}, \underline{\mu}_{2}\right)$ strictly prefers to be taxed under $S A$ than under FA.

Proof of Theorem 1. If one can show that SA is strictly preferred to FA on $\left[\bar{\mu}_{1}, \underline{\mu}_{2}\right)$, then the preference order can be extended to $\mu$ slightly less than $\bar{\mu}_{1}$ by continuity of the indirect profit function under SA.

Since $q_{1}^{S A}=q_{1}^{F A}=0$ for all $\mu \in\left[\bar{\mu}_{1}, \underline{\mu}_{2}\right)$, we need to compare $\pi^{S A}\left(0, q_{2}^{S A}\right)$ with $\pi^{F A}\left(0, q_{2}^{F A}\right)$. Note that

$$
\pi^{S A}\left(0, q_{2}^{S A}\right)-\pi^{F A}\left(0, q_{2}^{F A}\right)=\pi^{S A}\left(0, q_{2}^{S A}\right)-\pi^{S A}\left(0, q_{2}^{F A}\right)+\pi^{S A}\left(0, q_{2}^{F A}\right)-\pi^{F A}\left(0, q_{2}^{F A}\right) .
$$

Then note that $\pi^{S A}\left(0, q_{2}^{S A}\right) \geq \pi^{S A}\left(0, q_{2}^{F A}\right)$ because $q_{2}^{S A}$ is profit-maximizing under SA while $\pi^{S A}\left(0, q_{2}^{F A}\right)-\pi^{F A}\left(0, q_{2}^{F A}\right)=\Delta\left(t_{1}, \mathrm{t}_{2}\right) q_{2}^{F A}>0$ because for all $q_{2}, L_{2}^{S A}\left(q_{2}\right)=L_{2}^{F A}\left(0, q_{2}\right)$ and $K_{2}^{S A}\left(q_{2}\right)=K_{2}^{F A}\left(0, q_{2}\right)$, and because of the strict convexity of $C(\cdot)$. Thus, any firm with $\mu \in\left[\bar{\mu}_{1}, \underline{\mu}_{2}\right)$ will strictly prefer SA over FA.

Theorem 3. Assume that at $t_{2}=t_{1}$, a firm with marginal cost of capital $\mu$ and productivity 
parameter $\theta$ produces strictly positive output in both countries. For $t_{2}$ sufficiently close to $t_{1}$, country symmetry and apportionment formula symmetry imply that

$$
\begin{aligned}
\Pi^{S A}\left(t_{1}, t_{2}, \cdot\right)-\Pi^{F A}\left(t_{1}, t_{2}, \cdot\right)= & \frac{\left(t_{2}-t_{1}\right)^{2}}{2} \cdot\left[\frac{-\mu^{2}}{2\left(1-t_{1}\right)^{3} r_{1}^{\prime \prime}} \cdot\left(K_{2}^{S A} / q_{2}^{S A}+1\right)^{2}+\frac{w_{2}}{2} \frac{\partial L_{2}^{S A}}{\partial t_{2}}+\frac{q_{2}^{S A}}{C^{\prime \prime}(0)}+\frac{2 \lambda_{1}^{2} \pi^{0^{2}}}{\left(1-t_{1}\right) r_{1}^{\prime \prime}}\right] \\
& +O\left(\left(t_{2}-t_{1}\right)^{3}\right)
\end{aligned}
$$

where all output and input quantities are calculated at $t_{2}=t_{1}$.

Proof of Theorem 3.

Recall that $\Pi^{S A}\left(t_{1}, t_{1}\right)=\Pi^{F A}\left(t_{1}, t_{1}\right)$ for all $t_{1}$. Consider values of $t_{1}$ for which a firm with parameters $\mu$ and $\theta$ produces strictly positive quantities in each country when $t_{2}=t_{1}$. Given (4) and (7),

$$
\partial \Pi^{S A} / \partial t_{2}=-\left(r_{2}\left(q_{2}^{S A}\right)-w_{2} L_{2}^{S A}\left(q_{2}^{S A}, t_{2}\right)-w_{1} \theta q_{2}^{S A}\right)+\partial \Delta / \partial t_{2} \cdot q_{2}^{S A}
$$

where $\partial \Delta / \partial t_{2}=\left(C^{\prime}\right)^{-1}\left(t_{2}-t_{1}\right)=0$ at $t_{2}=t_{1}$ and

$$
\partial \Pi^{F A} / \partial t_{2}=(\lambda-1)\left(r_{1}+r_{2}-w_{1}\left(L_{1}^{F A}+\theta\left(q_{1}^{F A}+q_{2}^{F A}\right)\right)-w_{2} L_{2}^{F A}\right)=(\lambda-1) \pi^{0} .
$$

$\left(K_{i}^{S A}\left(q_{i}\right), L_{i}^{S A}\left(q_{i}\right)\right)$ solves $F(k, l)=q_{i}$ and $F_{K}(k, l) / \mu=F_{L}(k, l) /\left(1-t_{i}\right) w_{i}$ and $\left(K_{i}^{F A}\left(q_{1}, q_{2}\right), L_{i}^{F A}\left(q_{1}, q_{2}\right)\right)$ solves $F(k, l)=q_{i}$ and $F_{K}(k, l) / \mu=F_{L}(k, l) /(1-T) w_{i}$.

Under the Symmetry Assumption, $q_{i}^{S A}=q_{i}^{F A}, L_{i}^{S A}=L_{i}^{F A}, K_{i}^{S A}=K_{i}^{F A}$, and $\lambda=1 / 2$ so $\partial \Pi^{S A}\left(t_{1}, t_{1}\right) / \partial t_{2}=\partial \Pi^{F A}\left(t_{1}, t_{1}\right) / \partial t_{2}$. Thus, the second-order Taylor series expansion of $\Pi^{S A}\left(t_{1}, t_{2}\right)-\Pi^{F A}\left(t_{1}, t_{2}\right)$ about $t_{2}=t_{1}$ implies

$$
\Pi^{S A}\left(t_{1}, t_{2}\right)-\Pi^{F A}\left(t_{1}, t_{2}\right)=\left(t_{2}-t_{1}\right)^{2}\left(\partial^{2} \Pi^{S A} / \partial t_{2}^{2}-\partial^{2} \Pi^{F A} / \partial t_{2}^{2}\right) / 2+O\left(\left(t_{2}-t_{1}\right)^{3}\right) .
$$

Differentiating (A.7) implies

$$
\begin{aligned}
\partial^{2} \Pi^{S A} / \partial t_{2}^{2}= & {\left[-\left(r_{2}^{\prime}-w_{2} \cdot \partial L_{2}^{S A} / \partial q_{2}-w_{1} \theta\right)+\partial \Delta / \partial t_{2}\right] \cdot \partial q_{2}^{S A} / \partial t_{2} } \\
& +\partial^{2} \Delta / \partial t_{2}^{2} \cdot q_{2}^{S A}+w_{2} \partial L_{2}^{S A} / \partial t_{2}
\end{aligned}
$$

where $\partial^{2} \Delta\left(t_{1}, t_{1}\right) / \partial t_{2}^{2}=1 / C^{\prime \prime}(0)$ and the first-order condition with respect to $q_{2}$ implies

$$
\left(1-t_{1}\right)\left(r_{2}^{\prime}-w_{2} \cdot \partial L_{2}^{S A} / \partial q_{2}-w_{1} \theta\right)=\mu\left(\partial K_{2}^{S A} / \partial q_{2}+1\right)
$$

at $t_{2}=t_{1}$. 
Under constant returns to scale, comparative statics calculations imply that

$$
\begin{aligned}
& \partial K_{2}^{S A}\left(q_{2} ; t_{1}, t_{1}\right) / \partial q_{2}=K_{2}^{S A} / q_{2}^{S A}, \\
& \partial L_{2}^{S A} / \partial t_{2}=\frac{-w_{2} F_{K}^{2}\left(K_{2}^{S A}\right)^{2}}{F_{L L} q_{2}^{S A}\left(\mu K_{2}^{S A}+\left(1-t_{1}\right) w_{2} L_{2}^{S A}\right)},
\end{aligned}
$$

and

$$
\partial q_{2}^{S A}\left(t_{1}, t_{1}\right) / \partial t_{2}=\mu\left(\partial K_{2}^{S A} / \partial q_{2}+1\right) /\left(\left(1-t_{1}\right)^{2} r_{2}^{\prime \prime}\right) .
$$

Therefore,

$$
\left.\frac{\partial^{2} \Pi^{S A}}{\partial t_{2}^{2}}\right|_{t_{2}=t_{1}}=\frac{-\mu^{2}}{\left(1-t_{1}\right)^{3} r_{2}^{\prime \prime}} \cdot\left(\frac{K_{2}^{S A}}{q_{2}^{S A}}+1\right)^{2}+w_{2} \frac{\partial L_{2}^{S A}}{\partial t_{2}}+\frac{q_{2}^{S A}}{C^{\prime \prime}(0)} .
$$

The first term in (A.15) represents the output distortion induced by a change in $t_{2}$, the second term represents the distortion in the per-unit amount of marginal profits shifted with respect to $t_{2}$, and the last term represents distortions in the composition of capital and labor employed in country 2 .

Differentiating (A.8) implies

$$
\begin{aligned}
\partial^{2} \Pi^{F A} / \partial t_{2}^{2}= & (\lambda-1)\left(r_{1}^{\prime}-w_{1}\left(\partial L_{1}^{F A} / \partial q_{1}+\theta\right)-w_{2} \partial L_{2}^{F A} / \partial q_{1}\right) \cdot \partial q_{1}^{F A} / \partial t_{2}+ \\
& (\lambda-1)\left(r_{2}^{\prime}-w_{1}\left(\partial L_{1}^{F A} / \partial q_{2}+\theta\right)-w_{2} \partial L_{2}^{F A} / \partial q_{2}\right) \cdot \partial q_{2}^{F A} / \partial t_{2}+ \\
& \left(\lambda_{1} \cdot \partial q_{1}^{F A} / \partial t_{2}+\lambda_{2} \cdot \partial q_{2}^{F A} / \partial t_{2}\right) \pi^{0}+ \\
& (1-\lambda)\left[w_{1} \partial L_{1}^{F A} / \partial t_{2}+w_{2} \partial L_{2}^{F A} / \partial t_{2}\right]
\end{aligned}
$$

where the first-order conditions with respect to $q_{1}$ and $q_{2}$ are

$$
\begin{gathered}
(1-T)\left(r_{1}^{\prime}-w_{1}\left(\partial L_{1}^{F A} / \partial q_{1}+\theta\right)-w_{2} \partial L_{2}^{F A} / \partial q_{1}\right)+\lambda_{1}\left(t_{2}-t_{1}\right) \pi^{0} \\
-\mu\left(\partial K_{1}^{F A} / \partial q_{1}+\partial K_{2}^{F A} / \partial q_{1}+1\right)=0
\end{gathered}
$$

and

$$
\begin{gathered}
(1-T)\left(r_{2}^{\prime}-w_{1}\left(\partial L_{1}^{F A} / \partial q_{2}+\theta\right)-w_{2} \partial L_{2}^{F A} / \partial q_{2}\right)+\lambda_{2}\left(t_{2}-t_{1}\right) \pi^{0} \\
-\mu\left(\partial K_{1}^{F A} / \partial q_{2}+\partial K_{2}^{F A} / \partial q_{2}+1\right)=0 .
\end{gathered}
$$

Under constant returns to scale, comparative statics calculations imply that at $t_{2}=t_{1}$

$$
\partial K_{i}^{F A} / \partial q_{i}=K_{i}^{F A} / q_{i}
$$




$$
\begin{aligned}
& \partial L_{i}^{F A} / \partial t_{2}=\frac{-(1-\lambda) w_{i} F_{K}^{2}\left(K_{i}^{F A}\right)^{2}}{F_{L L} q_{i}^{F A}\left(\mu K_{i}^{F A}+\left(1-t_{1}\right) w_{i} L_{i}^{F A}\right)}, \\
& \partial K_{i}^{F A} / \partial q_{j}=0
\end{aligned}
$$

and

$$
\partial q_{i}^{F A} / \partial t_{2}=\frac{\frac{(1-\lambda) \mu}{\left(1-t_{1}\right)}\left(\frac{K_{i}^{F A}}{q_{i}^{F A}}+1\right)-\lambda_{i} \pi^{0}}{\left(1-t_{1}\right) r_{i}^{\prime \prime}}
$$

Note: In general, the numerator for $\partial q_{i}^{F A} / \partial t_{2}$ includes the terms $\left(1-t_{1}\right) w_{1} \cdot \partial^{2} L_{j}^{F A} / \partial t_{2} \partial q_{i}+\mu \partial^{2} K_{j}^{F A} / \partial t_{2} \partial q_{i}$ for both $j=i$ and $j \neq i$. When $j \neq i$, the expression equals zero at $t_{2}=t_{1}$. When $j=i$, the expression equals zero at $t_{2}=t_{1}$ under constant returns to scale. Therefore, given country and formula symmetry, substituting (A.17) - (A.22) into (A.16) implies that

$$
\frac{\partial^{2} \Pi^{F A}\left(t_{1}, t_{1}\right)}{\partial t_{2}^{2}}=\frac{-\mu^{2}}{2\left(1-t_{1}\right)^{3} r_{1}^{\prime \prime}}\left(\frac{K_{1}^{F A}}{q_{1}^{F A}}+1\right)^{2}+\frac{1}{2}\left[w_{1} \frac{\partial L_{1}^{F A}}{\partial t_{2}}+w_{2} \frac{\partial L_{2}^{F A}}{\partial t_{2}}\right]-\frac{\left(\lambda_{1}^{2}+\lambda_{2}^{2}\right) \pi^{0^{2}}}{\left(1-t_{1}\right) r_{1}^{\prime \prime}}
$$

Using (A.13) and (A.20), the symmetry assumptions also imply that $\partial L_{2}^{S A} / \partial t_{2}=\partial L_{1}^{F A} / \partial t_{2}+\partial L_{2}^{F A} / \partial t_{2}$. Thus, substituting (A.15) and (A.23) into (A.9) yields (13).Q.E.D.

Theorem 4. Assume that at $t_{2}=t_{1}$, a firm with marginal cost of capital $\mu$ and productivity parameter $\theta$ produces strictly positive output in both countries. Then country symmetry and apportionment formula symmetry imply that

$$
T R_{1}^{S A}\left(t_{1}, t_{2}\right)-T R_{1}^{F A}\left(t_{1}, t_{2}\right)=t_{1}\left(t_{2}-t_{1}\right)\left(\frac{\partial^{2} \Pi^{S A}\left(t_{1}, t_{1}\right)}{\partial t_{2}^{2}}-\frac{\partial^{2} \Pi^{F A}\left(t_{1}, t_{1}\right)}{\partial t_{2}^{2}}\right)+O\left(\left(t_{2}-t_{1}\right)^{2}\right)
$$

and

$$
T R_{2}^{S A}\left(t_{1}, t_{2}\right)-T R_{2}^{F A}\left(t_{1}, t_{2}\right)=t_{2}\left(t_{1}-t_{2}\right)\left[\frac{\partial^{2} \Pi^{S A}\left(t_{1}, t_{1}\right)}{\partial t_{2}^{2}}-\frac{\partial^{2} \Pi^{F A}\left(t_{1}, t_{1}\right)}{\partial t_{2}^{2}}\right]+O\left(\left(t_{2}-t_{1}\right)^{2}\right)
$$

where $\partial L_{2}^{S A} / \partial t_{2}$ is evaluated at $t_{2}=t_{1}$

Proof of Theorem 4. 
Total revenue paid to country 1 from a firm operating under SA equals

$$
T R_{1}^{S A}=t_{1}\left[r_{1}-w_{1}\left(L_{1}^{S A}+\theta q_{1}^{S A}\right)+\partial \Delta / \partial t_{2} \cdot q_{2}^{S A}\right]
$$

and total revenue paid to country 1 from a firm operating under SA equals

$$
T R_{1}^{F A}=\lambda t_{1} \pi^{0}=\lambda t_{1}\left[r_{1}+r_{2}-w_{1} \theta\left(q_{1}^{F A}+q_{2}^{F A}\right)-w_{1} L_{1}^{F A}-w_{2} L_{2}^{F A}\right] .
$$

Total revenue paid to country 2 from a firm operating under SA equals

$$
T R_{2}^{S A}=t_{2}\left[r_{2}-w_{2} L_{2}^{S A}-w_{1} \theta q_{2}^{S A}-\partial \Delta / \partial t_{2} \cdot q_{2}^{S A}\right]
$$

and total revenue paid to country 2 from a firm operating under FA equals

$$
T R_{2}^{F A}=(1-\lambda) t_{2} \pi^{0}=(1-\lambda) t_{2}\left[r_{1}+r_{2}-w_{1} \theta\left(q_{1}^{F A}+q_{2}^{F A}\right)-w_{1} L_{1}^{F A}-w_{2} L_{2}^{F A}\right] .
$$

This proof will derive and compare the first-order Taylor series expansions of (A.24 - A.27).

Country symmetry, formula symmetry, and $t_{2}=t_{1}$ imply $\left(C^{\prime}\right)^{-1}(0)=0$ and $\lambda=1 / 2$, so $T R_{1}^{S A}\left(t_{1}, t_{1}\right)=T R_{1}^{F A}\left(t_{1}, t_{1}\right)$ and $T R_{2}^{S A}\left(t_{2}, t_{2}\right)=T R_{2}^{F A}\left(t_{2}, t_{2}\right)$ while the partial derivative of country $i$ 's tax revenue function with respect to $t_{j}$ can differ for both countries.

Beginning with country $1,(\mathrm{~A} .8)$ implies that $\partial^{2} \Pi^{F A}\left(t_{1}, t_{2}\right) / \partial t_{2}^{2}=d\left(\lambda \pi^{0}\right) / d t_{2}-d \pi^{0} / d t_{2}$ while $\partial T R_{1}^{F A}\left(t_{1}, t_{2}\right) / \partial t_{2}=t_{1} \cdot d\left(\lambda \pi^{0}\right) / d t_{2}$ so $\partial T R_{1}^{F A}\left(t_{1}, t_{2}\right) / \partial t_{2}=t_{1}\left(\partial^{2} \Pi^{F A}\left(t_{1}, t_{2}\right) / \partial t_{2}^{2}+d \pi^{0} / d t_{2}\right)$. At $t_{2}=t_{1}$, country and formula symmetry imply $d \pi^{0} / d t_{2}=\mu^{2}\left(1+K_{2}^{F A} / q_{2}^{F A}\right)^{2} /\left(\left(1-t_{1}\right)^{3} r_{2}^{\prime \prime}\right)-w_{2} \cdot \partial L_{2}^{S A} / \partial t_{2}$ since $\partial \pi^{0} / \partial t_{2}=-2 w_{2} \partial L_{2}^{F A} / \partial t_{2}=-w_{2} \partial L_{2}^{F A} / \partial T=-w_{2} \partial L_{2}^{S A} / \partial t_{2}$. Under SA, differentiating (A.24) with respect to $t_{2}$ yields

$$
\partial T R_{1}^{S A} / \partial t_{2}=t_{1}\left[\partial \Delta / \partial t_{2} \cdot \partial q_{2}^{S A} / \partial t_{2}+\partial^{2} \Delta / \partial t_{2}^{2} \cdot q_{2}^{S A}\right]
$$

since $q_{1}^{S A}$ and $L_{1}^{S A}$ do not depend on $t_{2}$. Combined with (A.10), (A.11), and (A.14), (A.28) implies

$$
\partial T R_{1}^{S A}\left(t_{1}, t_{1}\right) / \partial t_{2}=t_{1}\left[\frac{\partial^{2} \Pi^{S A}}{\partial t_{2}^{2}}+\frac{\mu^{2}\left(1+K_{2}^{S A} / q_{2}^{S A}\right)^{2}}{\left(1-t_{1}\right)^{3} r_{2}^{\prime \prime}}-w_{2} \cdot \frac{\partial L_{2}^{S A}}{\partial t_{2}}\right] .
$$

Thus, at equal tax rates

$$
\frac{\partial T R_{1}^{S A}\left(t_{1}, t_{1}\right)}{\partial t_{2}}-\frac{\partial T R_{1}^{F A}\left(t_{1}, t_{1}\right)}{\partial t_{2}}=t_{1}\left[\frac{\partial^{2} \Pi^{S A}}{\partial t_{2}^{2}}-\frac{\partial^{2} \Pi^{F A}}{\partial t_{2}^{2}}\right] .
$$

Eq. (A.30) reveals that the first-order differences in country 1's tax revenues are based solely on 
the difference in firm profits given Theorem 3. Eq. (18) is generated by using (A.29) to derive the first-order Taylor series expansion of $T R_{1}^{S A}\left(t_{1}, t_{2}\right)-T R_{1}^{F A}\left(t_{1}, t_{2}\right)$ about $t_{2}=t_{1}$.

Turning now to country 2 tax revenues, $T R_{2}^{F A}=t_{2}(1-\lambda) \pi^{0}$ and $\partial \Pi^{F A} / \partial t_{2}=-(1-\lambda) \pi^{0}$.

Thus, $\partial T R_{2}^{F A} / \partial t_{2}=(1-\lambda) \pi^{0}+t_{2} \cdot d(1-\lambda) \pi^{0} / d t_{2}$ while $\partial^{2} \Pi^{F A} / \partial t_{2}^{2}=-d(1-\lambda) \pi^{0} / d t_{2}$.

Therefore,

$$
\partial T R_{2}^{F A} / \partial t_{2}=(1-\lambda) \pi^{0}-t_{2} \cdot \partial^{2} \Pi^{F A} / \partial t_{2}^{2}
$$

Differentiating (A.26) with respect to $t_{2}$ implies

$$
\begin{aligned}
\frac{\partial T R_{2}^{S A}}{\partial t_{2}}= & r_{2}-w_{2} L_{2}^{S A}-w_{1} \theta q_{2}^{S A}-\frac{\partial \Delta}{\partial t_{2}} \cdot q_{2}^{S A} \\
& +t_{2}\left[\left(r_{2}^{\prime}-w_{2} \frac{\partial L_{2}^{S A}}{\partial q_{2}}-w_{1} \theta\right) \frac{\partial q_{2}^{S A}}{\partial t_{2}}-w_{2} \frac{\partial L_{2}^{S A}}{\partial t_{2}}-\frac{\partial \Delta}{\partial t_{2}} \frac{\partial q_{2}^{S A}}{\partial t_{2}}-\frac{\partial^{2} \Delta}{\partial t_{2}^{2}} q_{2}^{S A}\right]
\end{aligned}
$$

while

$$
\frac{\partial^{2} \Pi^{S A}}{\partial t_{2}^{2}}=-\left(r_{2}^{\prime}-w_{2} \frac{\partial L_{2}^{S A}}{\partial q_{2}}-w_{1} \theta\right) \frac{\partial q_{2}^{S A}}{\partial t_{2}}+\frac{\partial \Delta}{\partial t_{2}} \cdot \frac{\partial q_{2}^{S A}}{\partial t_{2}}+\frac{\partial^{2} \Delta}{\partial t_{2}^{2}} q_{2}^{S A}+w_{2} \frac{\partial L_{2}^{S A}}{\partial t_{2}}
$$

Thus,

$$
\frac{\partial T R_{2}^{S A}}{\partial t_{2}}=r_{2}-w_{2} L_{2}^{S A}-w_{1} \theta q_{2}^{S A}-\frac{\partial \Delta}{\partial t_{2}} q_{2}^{S A}-t_{2} \frac{\partial^{2} \Pi^{S A}}{\partial t_{2}^{2}}
$$

and

$$
\frac{\partial T R_{2}^{S A}}{\partial t_{2}}-\frac{\partial T R_{2}^{F A}}{\partial t_{2}}=r_{2}-w_{2} L_{2}^{S A}-w_{1} \theta q_{2}^{S A}-\frac{\partial \Delta}{\partial t_{2}} q_{2}^{S A}-(1-\lambda) \pi^{0}+t_{2}\left(\frac{\partial^{2} \Pi^{F A}}{\partial t_{2}^{2}}-\frac{\partial^{2} \Pi^{S A}}{\partial t_{2}^{2}}\right) .
$$

Under country and formula symmetry and with $t_{2}=t_{1}, r_{2}-w_{2} L_{2}^{S A}-w_{1} \theta q_{2}^{S A}=(1-\lambda) \pi^{0}$ and $\partial \Delta / \partial t_{2}=0$ so

$$
\frac{\partial T R_{2}^{S A}}{\partial t_{2}}-\frac{\partial T R_{2}^{F A}}{\partial t_{2}}=t_{2}\left(\frac{\partial^{2} \Pi^{F A}}{\partial t_{2}^{2}}-\frac{\partial^{2} \Pi^{S A}}{\partial t_{2}^{2}}\right)
$$

Eq. (19) is generated by using (A.32) to derive the first-order Taylor series expansion of $T R_{2}^{S A}\left(t_{1}, t_{2}\right)-T R_{2}^{F A}\left(t_{1}, t_{2}\right)$ about $t_{2}=t_{1}$.

Q.E.D. 